


\title{
Interactions between financial incentives and health in the early retirement decision
}

\author{
Pilar García-Gómez ${ }^{a}$, Titus J. Galama ${ }^{b}$, Eddy van Doorslaer ${ }^{a}$, and Ángel López-Nicolás ${ }^{c}$ \\ ${ }^{a}$ Erasmus University Rotterdam (EUR), School of Economics, the Netherlands \\ ${ }^{b}$ USC, Center for Economic and Social Research (CESR), Los Angeles, USA \\ ${ }^{c}$ Universidad Politécnica de Cartagena, Spain
}

April 27, 2017

\begin{abstract}
We present a theory of the relation between health and retirement that generates testable predictions regarding the interaction of health, wealth and financial incentives in retirement decisions. The theory predicts (i) that wealthier individuals (compared to poorer individuals) are more likely to retire for health reasons (affordability proposition), and (ii) that health problems make older workers more responsive to financial incentives encouraging retirement (reinforcement proposition). We test these predictions using administrative data on older employees in the Dutch healthcare sector for whom we link adverse health events, proxied by unanticipated hospitalizations, to information on retirement decisions and actual incentives from administrative records of the pension funds. Exploiting unexpected health shocks and quasi-exogenous variation in financial incentives for retirement due to reforms, we account for the endogeneity of health and financial incentives. Making use of the actual individual pension rights diminishes downward bias in estimates of the effect of pension incentives. We find support for our affordability and reinforcement propositions. Both propositions require the benefits function to be convex, as in our data. Our theory and empirical findings highlight the importance of assessing financial incentives for their potential reinforcement of health shocks and point to the possibility that differences in responses to financial incentives and health shocks across countries may relate to whether the benefit function is concave or convex.
\end{abstract}

Keywords: pensions; health; retirement; disability; health investment; lifecycle model; health capital; optimal control

JEL Codes : C33, D91, H55, I10, I12, J00, J24, J26, J45, D91 


\section{Introduction}

There is a high degree of consensus that financial incentives deriving from social security and pension plans are important determinants of the retirement decision and that they have contributed to the general decrease in labour-force participation of older workers (Lumsdaine and Mitchell 1999; Gruber and Wise 2004). The generous early-retirement (ER) and disability-insurance (DI) arrangements prevailing in the 80s and 90s in the Netherlands have contributed substantially to the fall in labour-force participation of older workers (Lindeboom, 2012). As these arrangements were no longer deemed sustainable in the face of a rapidly aging population, and to ease the financial burden imposed on the social security system, several reforms were introduced, including the abolishment of ER schemes and a raise of the statutory retirement age (Euwals et al., 2010a). It is clear that the effectiveness of such policies depends on whether and how workers can respond to financial incentives such as pension wealth in the presence of health problems (Gruber and Wise 2004). Many studies find ill health to increase the likelihood of ER at older ages (Currie and Madrian 1999; Kerkhofs et al. 1999; Disney et al. 2006; Lindeboom 2012; Lindeboom and Kerkhofs 2009).

We contribute to both the theoretical and empirical literature in this area. So far, the theory that has most frequently sustained this literature is the Option Value retirement model proposed by Stock and Wise (1990). This model assumes that individuals compare in each period the expected net present value of retiring now with that of continuing to work and retiring at the optimal age in the future. The Option Value model does not consider health explicitly. In this paper we therefore develop a stylized model to integrate health into a model of retirement behavior and financial incentives. It is based on health-capital theory, the foundations of which were laid by the seminal work of Grossman $(1972 \mathrm{a}, \mathrm{b})$. In our extension of the model, (1) we assume diminishing returns to health investment, which addresses problems with commonly employed linear investment models (see Galama, 2015), and (2) we model longevity as a distinct choice variable (Ehrlich and Chuma 1990). We also introduce leisure time, retirement benefits and the choice of the optimal retirement age. In contrast to the extant literature (e.g., Stock and Wise, 1990), the resulting theory models the effect of financial incentives, health, wealth, and longevity on the optimal age of retirement explicitly.

The model not only generates the standard predictions, i.e. that the probability of retirement increases with wealth, with ill health and with more generous financial incentives for retirement, but also makes possible predictions about the interaction between health and financial incentives in retirement decisions. The theory predicts (i) that wealthier individuals (compared to poorer) are more likely to retire for health reasons (affordability proposition), and (ii) that health problems make older workers more responsive to financial incentives encouraging retirement (reinforcement proposition). Both propositions require the benefits function to be convex, as in our data.

We test these predictions on actual early-retirement decisions of workers in the Dutch health care sector in the presence of unanticipated health shocks, exploiting information 
on their pension wealth and financial incentives. We do this by linking accurate individual pension benefit information from the second largest pension fund in the Netherlands (Pensioenfonds Zorg en Welzijn, PFZW), to hospital admission diagnoses from hospital records and socio-demographic information from municipality registers. Rather than having to rely on estimates, we are able to use the actual pension wealth and financial incentives that are provided annually to the employees. This avoids downward biased estimation of the effects of financial incentives due to measurement error when variables are not directly observed and need to be proxied (Belloni and Alessie, 2009). We use unanticipated hospitalizations as quasi-exogenous adverse health events, and link these to subsequent early-retirement decisions.

For a five-year period (1999 to 2003) we exploit three sources of variation to identify the effects of financial incentives on retirement: (i) variation in early retirement replacement rates over successive birth cohorts due to the gradual transition from a previous actuarially unfair early-retirement scheme to an actuarially fair early-retirement scheme (Flexpensioen, FLEX; from January 1, 1999, replacement rates decreased by one percentage point per year of birth), (ii) variation in eligibility conditions depending on the year of birth and tenure (e.g., individuals born after 1948 are not eligible for the most generous scheme, and (iii) conditional on the year of birth, the individual variation in the duration and size of contributions to the scheme, resulting from differences in tenure and in the full/part-time employment history of individuals. By exploiting health variation that is arguably exogenous to labour-market outcomes by virtue of it being unexpected, we avoid the well-known problem of endogeneity of self-reported health variables (cf. e.g., Bound 1991). To this end, we selected a subset of hospital admissions for diagnoses that are likely to correspond to a new and unexpected health problem (conditional on the individual not having been hospitalized in the previous year).

The effects of financial incentives on (early) retirement have been widely documented (for a review, see, e.g., Lindeboom, 2012) and many studies have also found health (shocks) to have an impact on retirement (e.g., Currie and Madrian 1999; Kerkhofs et al. 1999; Disney et al. 2006; Lindeboom and Kerkhofs 2009; García-Gómez et al. 2013). Far fewer studies have looked at the interaction between financial incentives and health, because typically most surveys do not collect detailed information on both. Wise (2016) explores the relationship between the option value and retirement across health quintiles in twelve countries, and finds that the relationship between financial incentives and health differs across countries in both sign and significance. However, the lack of a comprehensive theory that models (early-)retirement decisions as a function of both health and financial incentives prevents the authors of the study to rationalize these cross-country differences. Of course, ER financial incentives may have an effect not only on the probability that an older worker transits into early retirement, but also on other exit routes. In our analysis we focus on the effect of ER incentives on transitions into ER. It seems reasonable to abstract from DI claiming behavior in our model since recent Dutch reforms have closed-off the substitute pathway of disability insurance as an exit route into early retirement (Euwals et al. 2012). 
Studies that focus on the effects of health on labour supply have mostly used self-reported health measures, which will lead to an overestimation of the impact of poor health on employment if health problems are over reported as a justification for inactivity. The use of self-reported health indicators to instrument for reported work incapacity may similarly cause bias in the same direction (Bound, 1991). Many of the previous studies had to rely on crude health controls, such as changes in self-reported health status, or other subjective health measures, rather than on data of actual medical events, since these were not available in socioeconomic surveys (Bound et al. 1999; Disney et al. 2006; Banks et al. 2007; Hagan et al. 2008; Roberts et al. 2010). In these studies, it was therefore not possible to assess whether ill health causes retirement due to reverse causality (work affects health) and due to unobservables that influence both health and work.

Adverse health shocks gathered from hospitalization data provide a source of unanticipated variation in health status, which can be used to identify the causal effect of health on work status (Lindeboom 2012, Lindeboom et al. 2016). Only a few studies have employed unanticipated health shocks to this end. Møller Dano (2005) uses road accidents recorded for a $10 \%$ sample of the Danish population and finds a significant effect on employment only for males, for whom the employment rate decreases by around $10 \%$ after an accident and does not recover in the subsequent six years. Halla and Zweimüller (2013) study accidents experienced on the way to and from work, which they argue are less likely to induce selection problems. They find negative effects on employment (4 percentage points on average) and on earnings, conditional on remaining employed. The effects are larger for individuals that are less attached to the labour market, such as females and blue-collar workers. García-Gómez et al. (2013) use acute hospitalizations for Dutch workers to identify the causal effects of health shocks on employment and on income. They show that, on average, an acute hospital admission lowers the employment probability by seven percentage points and results in a $30 \%$ loss of personal income for those entering DI two years after the shock. They also find that a health shock is both more likely to occur and to have a larger relative impact on employment and on income at the bottom of the income distribution. More recently, Dobkin et al. (2016) used U.S. non-pregnancy related hospital admissions - for individuals who were not recently hospitalized to study the impact of admissions on a wide range of economic consequences, including out-of pocket medical spending, unpaid medical bills, bankruptcy, earnings, income, access to credit, and consumer borrowing. They find that the elderly - who have health insurance coverage through Medicare and relatively little labour-market earnings - appear to suffer little or no economic consequences from hospital admissions. In our empirical analysis, we will also use data on hospitalizations and diagnoses to construct a measure of new and unanticipated health events and to investigate their effect on retirement.

The paper is organized as follows. In the next section, we discuss ER schemes in the Netherlands in general and in the health care sector in particular. Section 3 presents our theory of health, retirement and pension incentives and makes predictions. Section 4 presents our empirical strategy to evaluate the effects of financial incentives, health shocks, and their interaction, for ER transitions. Section 5 describes the data. Section 6 presents 
the results and section 7 summarizes and concludes.

\section{Early retirement (ER) in the Netherlands in 1999-2003}

In the period under consideration, retirees in the Netherlands received a flat-rate pay-as-you-go state pension, starting at age 65. The state pension was usually supplemented by a mandatory occupational pension that is capital funded and mostly defined benefit. Many sectors had early retirement schemes, independent of the capital-funded occupational pension until the late 90s. These were on a pay-as-you-go basis and were highly actuarially unfair: the implicit tax on continuing to work for one more year was about 100\% (Kapteyn and de Vos, 1999). Unions and employers organizations agreed to gradually switch to an actuarially fair early-retirement scheme (FLEX) from January 1, 1999, in the health care sector. Individuals claiming FLEX benefits at age 60 are entitled to $1.75 \%$ of their base salary for each year of participation. Individuals can claim early-retirement benefits through the FLEX scheme as soon as they become 55 or postpone until 65 with actuarially fair adjustments (Euwals et al, 2010b).

A transitional early-retirement scheme (OBU; Overbruggingsregeling Uitkeringen) was introduced for workers close to age sixty. In particular, workers born before 1949, who are currently not receiving a disability benefit and who have worked in the sector for at least ten years, became eligible for OBU benefits. The replacement rate is reduced by one percentage point for every next cohort entitled to OBU, i.e., workers born before 1939 get a replacement rate of $80 \%$ of their gross last salary, workers born in 1940 get $79 \%, \ldots$, and workers born in 1948 get $71 \%$ of their gross last salary. No adjustments were made for later retirement, thus postponement of benefits implied losing them.

Figure 1 shows the expected median pension benefit for a 55 year-old PFZW worker, for both the FLEX and OBU schemes. Note that financially the most attractive scheme up to retirement age 60 is FLEX and that the FLEX benefits function is convex with age. Between retirement ages 60 and 62 , the median individual would be better off choosing to retire under OBU, while after retirement age 62 the median individual would prefer FLEX again. The combination of FLEX and OBU creates a convex curve due to FLEX with a bump at age 60 (and a smaller bump at age 61) due to OBU.

Thus, the existence of the two retirement options generates a convex curve due to FLEX with a marked increase in the benefits function at retirement age 60 due to OBU, which is visualized in Figure 2, where we plot several centiles of the distribution of benefits, assuming that these 55 year-old individuals opt for the most beneficial scheme. The $50^{\text {th }}$ centile graph (triangles) corresponds to the pattern in Figure 1 . Note that the $5^{\text {th }}, 25^{\text {th }}$ and $75^{\text {th }}$ centile curves are also convex with a bump at age $60 .^{1}$

Not surprisingly, the actual, empirical hazard of retirement (Figure 3) shows a marked peak at retirement age 60 , from about $5 \%$ at retirement age 59 to slightly less than $50 \%$. The hazard is close to $40 \%$ at retirement age 61 and then stabilizes at about $10 \%$ thereafter.

\footnotetext{
${ }^{1}$ Only for the $75^{\text {th }}$ centile the curve turns concave after age 63 .
} 


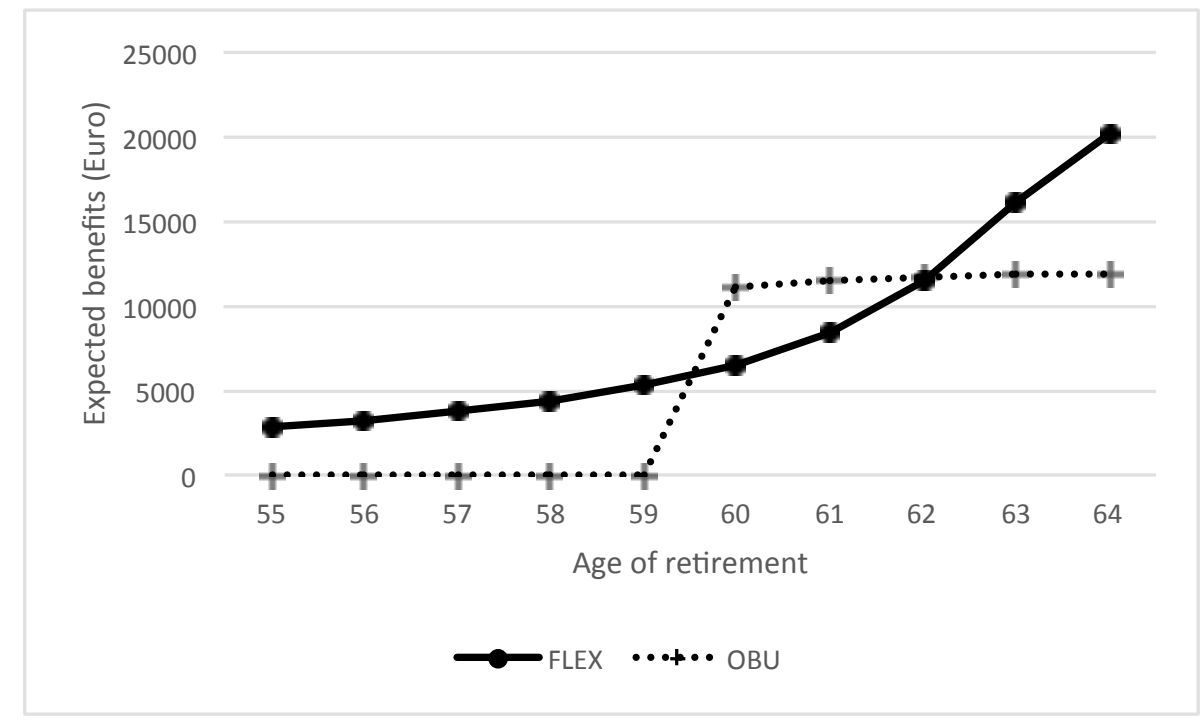

Figure 1: Expected median benefits of retiring at different ages, by early-retirement scheme. The figure shows the expected benefits at age 55 of the sample of individuals working at age 55, regardless of their later decisions. Authors' calculations based on the sample of workers aged 55 in PFZW during the period 1999-2002.

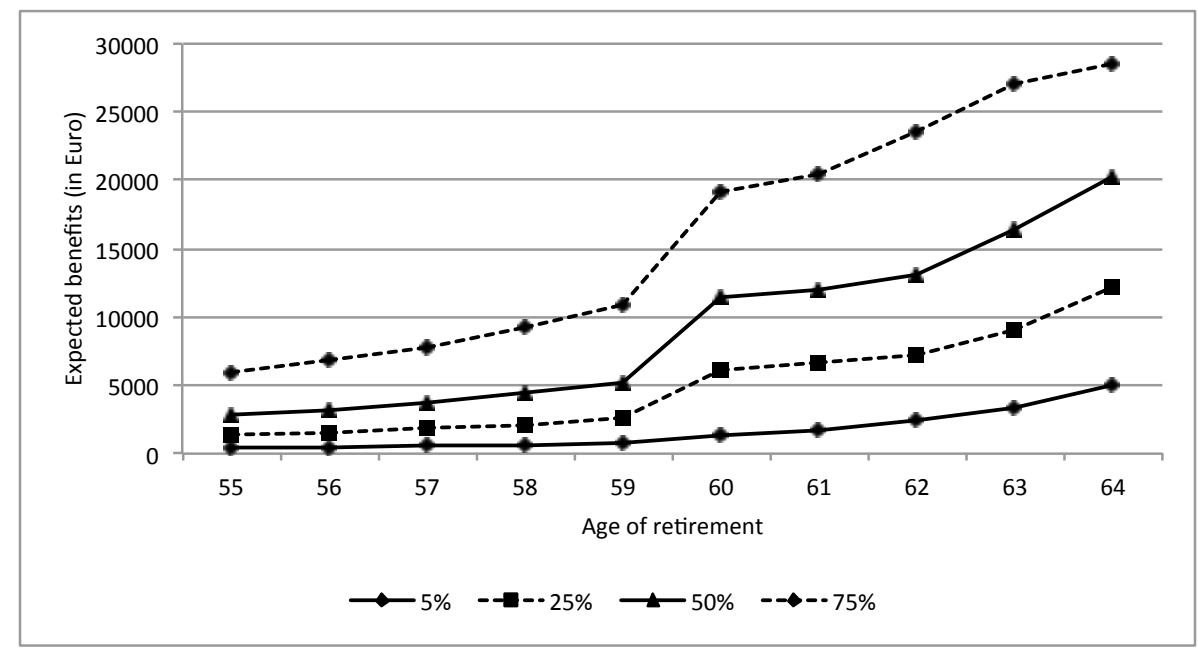

Figure 2: Distribution of expected benefits of retiring a different ages. The figure shows the expected benefits at age 55 of the sample of individuals working at age 55, regardless of their later decisions. For each individual, the incentives used are those from the program (FLEX or OBU) that is most beneficial. Authors' calculations based on the sample of workers aged 55 in PFZW during the period 1999-2002. 


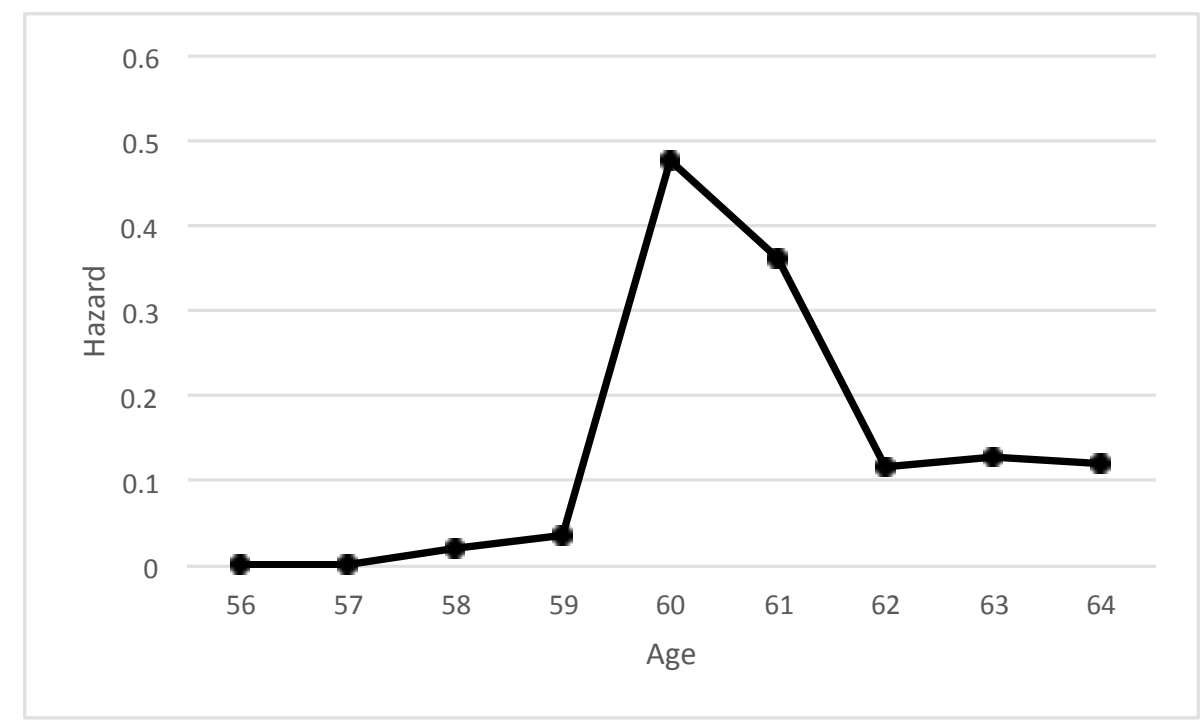

Figure 3: Empirical retirement hazard function. Authors' calculations based on the sample of individuals in PFZW during the period 1999-2002.

\section{A theory of health, retirement and longevity}

To inform our empirical analysis of the relation between health, financial incentives, and retirement we develop a theory of the role of financial incentives, health, wealth, and longevity. The foundation of the model is provided by the canonical theory of the demand for health, due to Grossman (1972a,b) (see also Galama 2015). In contrast to Grossman (1972a,b) we employ diminishing returns to health investment, which addresses the degeneracy of commonly employed linear investment models (Galama, 2015). We also model longevity as a choice variable (Ehrlich and Chuma 1990). We then introduce leisure time, retirement benefits, and the choice of the optimal retirement age, to arrive at a theory of health, wealth, financial incentives, retirement, and longevity. In contrast to the extant literature, the resulting theory models incentives, health, wealth, and longevity explicitly (as opposed to, e.g., the canonical model of retirement due to Stock and Wise, 1990 which compares value functions for different ages). ${ }^{2}$ Since our theory analyses optimal decisions, optimality conditions compare marginal benefits with marginal costs. Our theoretical model thus provides an alternative framework for analyzing retirement decisions with the advantage of making explicit the relations of interest (e.g., health, wealth, financial incentives, longevity and retirement in our case).

In the next sections we formulate the model (section 3.1), present the first-order

\footnotetext{
${ }^{2}$ These value functions, i.e. sums of future utility streams, are constructed using information about financial incentives, wealth and survival probabilities. The subtle difference is that these are "embedded" in these functions whereas our approach models them explicitly.
} 
conditions (section 3.2), analyze the optimality condition for the optimal age of retirement, and make predictions (section 3.3).

\subsection{Formulation}

Individuals maximize the life-time utility function

$$
\int_{0}^{R} U(t) e^{-\beta t} d t+\int_{R}^{T} U(t) e^{-\beta t} d t
$$

where $R$ is the age of retirement (endogenous), $T$ denotes total lifetime (endogenous), $\beta$ is a subjective discount factor and individuals derive utility $U[C(t), L(t), H(t)]$ from consumption $C(t)$, leisure time $L(t)$ and health $H(t)$. The utility function is increasing in each of its arguments and strictly concave.

The objective function (1) is maximized subject to the following dynamic constraints:

$$
\begin{aligned}
& \frac{\partial H(t)}{\partial t}=\mu_{I}(t) I(t)^{\alpha}-d(t) H(t), \\
& \frac{\partial A(t)}{\partial t}=\delta A(t)+Y[H(t)]-p_{C}(t) C(t)-p_{I}(t) I(t),
\end{aligned}
$$

the total time budget $\Omega$

$$
\Omega=\tau_{w}(t)+L(t)+s[H(t)],
$$

and initial and end conditions: $H(0), H(T), A(0)$ and $A(T)$ are given. An individual dies at age $T$ when health reaches a minimum health level $\left(H(T) \equiv H_{\min }\right)$ (Grossman 1972a,b).

Health capital $H(t)$ (equation 2) can be improved through investments in health $I(t)$ (remedial and preventive care, exercise) and deteriorates at the biological deterioration rate $d(t)$. The production process for health $f_{H}(t)=\mu_{I}(t) I(t)^{\alpha}$ is assumed to obey the law of diminishing returns $(0<\alpha<1)$ on investment $I(t)$ and has an efficiency $\mu_{I}(t)$.

Assets $\mathrm{A}(\mathrm{t})$ (equation 3 ) provide a return $\delta$ (return on capital), increase with income

$$
\begin{aligned}
Y[H(t)] & \equiv w(t)\{\Omega-L(t)-s[H(t)]\}, & & 0 \leq t<R \\
Y[H(t)] & \equiv b(R), & & R \leq t<T
\end{aligned}
$$

and decrease with expenditures on consumption $C(t)$ and investment $I(t)$ goods and services, purchased in the market at prices $p_{C}(t)$ and $p_{I}(t)$, respectively.

$\Omega$, the total time available in any period (equation 4 ), is the sum of all possible uses $\tau_{w}(t)$ (work), $L(t)$ (leisure), and $s[H(t)]$ (sick time; a decreasing function of health). Earnings during working life equal the wage rate $w(t)$ times the time spend working $\tau_{w}(t)$ (see equation 5). During retirement individuals do not work, i.e.

$$
\tau_{w}(t)=0
$$


and receive a state pension annuity $b(R)$, assumed to be a function of retirement age $R$.

Thus, we have the following optimal control problem: the objective function (1) is maximized with respect to the controls $C(t), L(t), I(t)$, the parameters $R$ and $T$, and subject to the constraints (2) to (7). The Lagrangian (see, e.g., Seierstad and Sydsaeter 1987, Caputo 2005) of this problem is:

$$
\Im=U[C(t), L(t), H(t)] e^{-\beta t}+q_{H}(t) \frac{\partial H(t)}{\partial t}+q_{A}(t) \frac{\partial A(t)}{\partial t}+\lambda_{\tau_{w}}(t) \tau_{w}(t),
$$

where $q_{H}(t)$ is the marginal value of health (associated with the differential equation (2) for health $H(t)), q_{A}(t)$ is the marginal value of wealth (associated with the differential equation (3) for assets $A(t)$ ), and $\lambda_{\tau_{w}}(t)$ is the multiplier associated with condition (7) $\left(\lambda_{\tau_{w}}(t)=0\right.$ if $\tau_{w}(t)>0$ and $\lambda_{\tau_{w}}(t)>0$ if $\left.\tau_{w}(t)=0\right)$. The conditions for optimal retirement $R$ and optimal longevity $T$ follow from the dynamic envelope theorem (e.g., Caputo 2005, p. 293):

$$
\begin{aligned}
\frac{\partial}{\partial R} \int_{0}^{T} \Im(t) d t & =\Im\left(R_{-}\right)-\Im\left(R_{+}\right)+\int_{0}^{T} \frac{\partial \Im(t)}{\partial R} d t=0, \\
\frac{\partial}{\partial T} \int_{0}^{T} \Im(t) d t & =\Im(T)=0,
\end{aligned}
$$

where $R_{-}$indicates the limit in which $R$ is approached from below and $R_{+}$the limit in which $R$ is approached from above. ${ }^{3}$ Further, the co-state variables $q_{A}(t)$ and $q_{H}(t)$ are continuous in $R$.

\subsection{First-order conditions}

The first-order conditions for consumption, leisure and health investment follow from setting the derivative of the Lagrangian (8) w.r.t. each control function to zero:

$$
\begin{aligned}
\frac{\partial U}{\partial C} & =q_{A}(t) p_{C}(t) e^{\beta t} & & 0 \leq t \leq T, \\
\frac{\partial U}{\partial L} & =q_{A}(t) w(t) e^{\beta t} & & 0 \leq t<R, \\
& =\lambda_{\tau_{w}}(t) e^{\beta t} & & R \leq t \leq T, \\
\pi_{I}(t) & =\frac{q_{H}(t)}{q_{A}(t)} & & 0 \leq t \leq T,
\end{aligned}
$$

where the marginal cost of health investment is defined as

$$
\pi_{I}(t) \equiv \frac{p_{I}(t) I(t)^{1-\alpha}}{\alpha \mu_{I}(t)} .
$$

\footnotetext{
${ }^{3}$ To the best of our knowledge, Ehrlich and Chuma (1990) were the first to explicitly model endogenous longevity in the health-capital literature using condition (10) and Kuhn et al. (2015) were the first to model endogenous retirement using condition (9). However, Kuhn et al. (2015) model health and longevity through a survival function. As a result there is no clear distinction between health and longevity.
} 
The dynamic equations for the marginal value of health $q_{H}(t)$ and the marginal value of wealth $q_{A}(t)$ follow from the conditions $-\partial q_{H}(t) / \partial t=\partial \Im(t) / \partial H(t)$ and $-\partial q_{A}(t) / \partial t=$ $\partial \Im(t) / \partial A(t)$. We have

$$
\begin{aligned}
\frac{\partial q_{A}(t)}{\partial t} & =-q_{A}(t) \delta & & 0 \leq t \leq T, \\
\frac{\partial q_{H}(t)}{\partial t} & =q_{H}(t) d(t)-\frac{\partial U}{\partial H} e^{-\beta t}+q_{A}(t) w(t) \frac{\partial s}{\partial H} & & 0 \leq t<R, \\
& =q_{H}(t) d(t)-\frac{\partial U}{\partial H} e^{-\beta t}+\lambda_{\tau_{w}}(t) \frac{\partial s}{\partial H} & & R \leq t \leq T .
\end{aligned}
$$

The three first-order conditions (11), (12), and (13) determine the optimal solutions of the controls consumption $C(t)$, leisure time $L(t)$, and health investment $I(t)$, respectively. The two dynamic equations (2) and (3) determine the state functions health capital $H(t)$ and wealth (assets) $A(t)$, and the two co-state equations (15) and (16) determine the marginal value of wealth $q_{A}(t)$ and of health $q_{H}(t)$. The optimal retirement age $R$ and optimal length of life $T$ are determined by the conditions (9) and (10). The initial and end conditions $H(0)$ and $H(T)=H_{\text {min }}$ determine $q_{H}(0)$, the initial and end conditions $A(0)$ and $A(T)$ determine $q_{A}(0)$, and $\lambda_{\tau_{w}}(t)$ is determined by condition (7)

$$
\tau_{w}(t)=\Omega-L(t)-s[H(t)]=0 .
$$

\subsection{Retirement}

Our interest lies primarily in understanding the relation between health, financial incentives, wealth and retirement. The condition (9) for optimal retirement $R$ requires us to consider the difference in the Lagrangian right before and right after retirement, $\Im\left(R_{-}\right)-\Im\left(R_{+}\right)$. Since health investment $I(t)$ is determined by the ratio of the marginal value of health $q_{H}(t)$ to the marginal value of wealth $q_{A}(t)$ (see 13), both of which are continuous in $R$, health investment is also continuous in $R$, i.e. $I\left(R_{-}\right)=I\left(R_{+}\right)$. This is not true, by construction, for leisure time $L(t)$ as individuals work right before retirement, but don't work right after retirement. ${ }^{4}$ Thus leisure time exhibits a discrete jump upward at retirement, $L\left(R_{+}\right)>L\left(R_{-}\right)$. The model predicts that consumption also jumps at retirement as the jump in leisure time may change the marginal utility of consumption (see equation 11). This is consistent with the findings that U.S. and British households reduce consumption near retirement (Banks, Blundell and Tanner, 1998; Bernheim, Skinner and Weinberg, 2001), which would suggest that on average $\partial^{2} U / \partial C \partial L>0 .^{5}$

\footnotetext{
${ }^{4}$ I.e. $\tau_{w}\left(R_{-}\right)>0 \Rightarrow L\left(R_{-}\right)<\Omega-s[H(R)]=L\left(R_{+}\right)$(note that sick time is continuous in $R$ as health $H(R)$ is continuous in $R)$.

${ }^{5}$ Because the mechanisms underlying this observed drop in consumption at retirement are not well understood, and might be inconsistent with the life-cycle model, this drop in consumption at retirement has been referred to as the retirement-consumption puzzle. In a series of papers Hurd and Rohwedder (2003, 2006, 2013), using panel data, have explored several possible mechanisms explaining the consumption decline. They find that prior to retirement workers anticipated on average a decline of $13.3 \%$ in
} 
With the above and noting that state and co-state functions are continuous in $R$, and $\lambda_{\tau_{w}}(R) \tau_{w}(R)=0$, the condition (9) reduces to

$$
\begin{aligned}
Y\left[H\left(R_{-}\right)\right] & =b(R)-\frac{\partial b(R)}{\partial R} \frac{1}{\delta}\left[1-e^{-\delta(T-R)}\right]+\frac{1}{q_{A}(R)}\left[U\left(R_{+}\right)-U\left(R_{-}\right)\right] e^{-\beta R} \\
& +p_{C}(R)\left[C\left(R_{-}\right)-C\left(R_{+}\right)\right]
\end{aligned}
$$

where $Y\left[H\left(R_{-}\right)\right]=w(R) \tau_{w}\left(R_{-}\right)=w(R)\left\{\Omega-L\left(R_{-}\right)-s[H(R)]\right\}$, and we have replaced the limits $R_{-}$and $R_{+}$with $R$ for functions that are continuous in $R$. Briefly, the optimal age of retirement $R$ requires the benefits of working, consisting of labour income $Y\left[H\left(R_{-}\right)\right]=w(R) \tau_{w}\left(R_{-}\right)$, to equal the benefits of retirement, consisting of the pension benefit (first term on the RHS), the cost of delayed retirement (second term on the RHS), utility from increased leisure time (third term on the RHS), and savings from reduced consumption (fourth term on the RHS). Individuals remain in retirement if benefits from retirement exceed benefits from work and will re-enter the labour force if this condition no longer holds. We explain the optimality condition (18) for the age of retirement $R$ in more detail below.

Consider first the case where utility $U(t)$ is continuous in $R^{6}$ and the state pension annuity $b(R)=b$ is independent of the age of retirement. The decision to retire is then simply determined by the age $R$ at which earnings from retirement $b$ exceed, for the first time, earnings from work $Y[H(t)]=w(t) \tau_{w}(t)$ (labour income $Y[H(t)]$ declines due to worsening health with age). Generous retirement (e.g., social security) benefits $b$ and low labour income $Y[H(t)]$ encourage early retirement.

If the pension benefit $b(R)$ is a function of the age of retirement $R$, it may be attractive for individuals to delay retirement in order to receive higher benefits $b(R)$ per period. However, this comes at the cost of a shortened horizon $T-R$ over which these benefits are received, as reflected in the term $(\partial b(R) / \partial R) \frac{1}{\delta}\left[1-e^{-\delta(T-R)}\right]$. Steeply declining pension benefits $(-\partial b(R) / \partial R$ large) induce retirement by raising the benefit $b(R)-(\partial b(R) / \partial R) \frac{1}{\delta}\left[1-e^{-\delta(T-R)}\right]$ of retirement. Indeed, Lazear (1986) finds that pensions are typically actuarially unfair, and that sharp decreases in the actuarial value of retirement with continued work, are used as a device by employers to induce earlier retirement of workers.

spending and after retirement they recollected a decline of $12.9 \%$ : thus widespread surprise (inconsistent with the assumption of rational behavior underlying life-cycle models) is not the explanation for the retirement-consumption puzzle. Workers with substantial wealth both anticipated and recollected a decline. In the low-wealth population where spending did decline at higher rates, the main explanation for the decline appears to be a high rate of early retirement due to poor health (poor health is found to be associated with above-average declines). Hurd and Rohwedder conclude that conventional models of economic behavior can account for the observed changes in consumption near retirement, with primary mechanisms being the cessation of work-related expenses, unexpected retirement due to a health shock or the substitution of time for spending.

${ }^{6}$ Hence there are no jumps in leisure time $L(t)$ or in consumption $C(t)$ at $R$. This is for example the case for a utility function that is additively separable in its arguments. 
Further, leisure time jumps at retirement providing additional utility in retirement. If $\partial^{2} U / \partial C \partial L \sim 0$ (consumption and leisure are neither complements nor substitutes in utility), the monetary equivalent of this additional utility from leisure consist of the discounted difference in utility divided by the marginal value of wealth at the age of retirement $\frac{1}{q_{A}(R)}\left[U\left(R_{-}\right)-U\left(R_{+}\right)\right] e^{-\beta R}$. Because individuals value leisure in retirement they do not need to be compensated dollar for dollar in income, and retirement occurs while pension benefits are less than labour income.

In addition, the marginal utility of consumption might change as a result of the jump in leisure. As discussed earlier, plausibly consumption and leisure are complements in utility $\partial^{2} U / \partial C \partial L>0$, so that greater leisure time $L\left(R_{+}\right)>L\left(R_{-}\right)$reduces the demand for consumption $C\left(R_{+}\right)<C\left(R_{-}\right)$. This reduces the gain in utility from leisure $U\left(R_{+}\right)-U\left(R_{-}\right)$, but has the advantage of reducing the cost of consumption $p_{C}(R)\left[C\left(R_{-}\right)-C\left(R_{+}\right)\right] .^{7}$

Mechanisms The condition (18) for the age of retirement highlights several mechanisms. Existing theories of retirement (e.g., Stock and Wise, 1990) model the retirement decision as the trade-off between retirement wealth (e.g., the net present value $[\mathrm{NPV}]$ of the pension annuity, first and second terms on the RHS), foregone labour earnings (term on the left-hand side [LHS]), and utility from additional leisure time (third term on the RHS). Such models are useful for understanding the role of financial incentives as mechanisms to dis- or encourage postponing retirement. In our theory financial incentives are modeled through the functional dependence (or structure) of the pension annuity $b(R)$ on the retirement age $R$. The functional form is obtained from pension plan rules such as the earnings replacement rate at each age and the early and normal (or full) statutory retirement ages. Typically, before the age of early retirement pensions cannot be claimed and retirement is unattractive. Between the early and normal (or full) retirement ages the replacement rate increases with delayed retirement, which induces some individuals to delay retirement till the normal retirement age. Spikes in the retirement hazard are often observed at the early and normal statutory retirement ages (see Figure 3 for our setting).

The novel aspect of our theory is that we not only model financial incentives through $b(R)$, but also explicitly model the role of health $H(t)$, health investment $I(t)$ (e.g., medical care), wealth $A(t)$ (other than pension wealth $\int_{R}^{T} b(R) e^{-\delta t} d t$ ), and longevity $T$. It is the inclusion of these additional determinants of retirement, as well as their interaction with financial incentives, that allows for the modeling of several mechanisms into retirement that have largely remained unexplored. Our theory also highlights an additional benefit of retirement, consisting of potential reductions in consumption (fourth term on the RHS).

\footnotetext{
${ }^{7}$ The change in utility arguably remains positive (higher utility immediately following retirement; $U\left(R_{+}\right)-U\left(R_{-}\right)>0$ ) as the effect of a change in consumption on utility is a second-order effect (and thus relatively small), operating through the effect that a change in leisure time has on the marginal utility of consumption and thereby on the level of consumption and on utility, while the effect of a jump in leisure has a first-order (direct) effect on utility (and is thus plausibly larger).
} 
We explain all of this in more detail in the next section.

Stylized representation Figure 4 provides a stylized representation of the optimality condition for retirement (18). The optimal age of retirement $R^{*}$ is the age at which the marginal benefits of work, consisting of earnings $Y\left[H_{H}(R)\right]$ (horizontal dotted line and first term on the LHS of 18), where $H_{H}(R)$ indicates the health of a healthy individual (we will make comparisons later with an unhealthy individual), equal the marginal benefits of retirement. The latter consist of the pension benefit (solid line labeled $b(R)$ and first term on the RHS of 18) minus the cost of delaying retirement (second term on the RHS), utility from additional leisure (third term on the RHS), and potential cost reductions due to reduced consumption (fourth term on the RHS). These additional marginal benefits of retirement (second, third and fourth terms on the RHS of 18) are labeled "Rest" in Figure 4. For simplicity both the marginal benefit of work $Y\left[H_{H}(R)\right]$ and the remaining marginal benefits of retirement (labeled "Rest") are shown as being constant with retirement age.

Typically, before the age of early retirement, pensions cannot be claimed and $b(R)$ is small (shown for simplicity as $b(R)$ being zero), benefits $b(R)$ then rise between the early and normal (or full) retirement ages, after which they typically modestly increase or modestly decline (represented by the horizontal dependence for large $R$ ). We show a convex relationship, consistent with the early retirement scheme (see Figures 1 and 2).

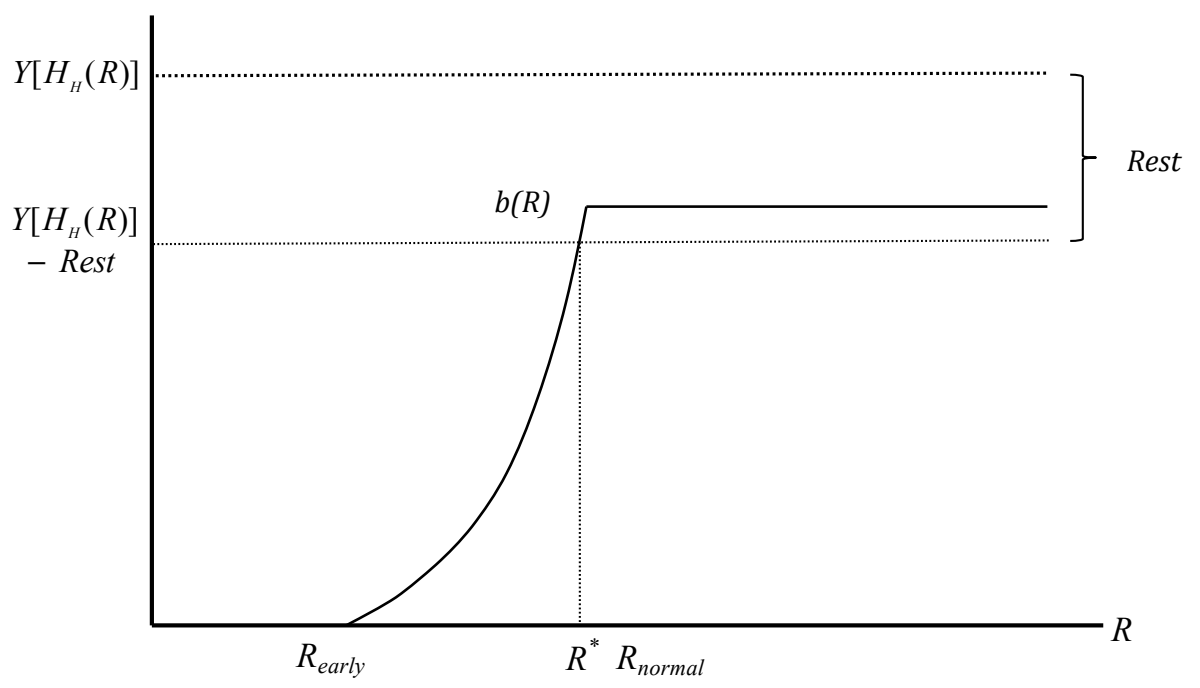

Figure 4: Stylized representation of the optimality condition for retirement (18).

When an individual is working, the marginal benefits of work exceed those of retirement. In Figure 4 this represents values of $R$ to the left of $R^{*}$ for which $b(R)$ is smaller than $Y\left[H_{H}(R)\right]$ - Rest (the lower horizontal dotted line). The optimal age of retirement $R^{*}$ is the age at which the $b(R)$ curve crosses $Y\left[H_{H}(R)\right]-$ Rest. 
For a healthy individual, and a typical replacement rate of 72 percent $b(R)=$ $0.72 Y\left[H\left(R_{-}\right)\right],{ }^{8}$ the remaining terms (second to fourth on the RHS, i.e. what we term "Rest") combine to about 28 percent of the level of earnings just before retirement $Y\left[H\left(R_{-}\right)\right]$. Thus typically the pension benefit $b(R)$ is the dominant benefit of retirement (RHS of 18) and retirement occurs as a result of financial incentives, i.e. the optimal age of retirement is most sensitive to the pension structure (or functional dependence of $b(R)$ on $R$ ).

Wealth Figure 5 provides a stylized representation of the effect of wealth on the optimal age of retirement (18), conditional on health status $H_{H}(R)$ for a healthy individual. The comparison here is between two identical individuals (importantly, with identical health) who differ in their private and/or pension wealth. Wealth decreases the marginal value of wealth $q_{A}(R),{ }^{9}$ thereby increasing the utility from additional leisure (third term on the RHS of 18) and shifting the horizontal line $Y\left[H_{H}(R)\right]$ down. Wealthy individuals retire earlier as they value leisure relatively more: all else equal, they can be expected to retire earlier: wealth has a positive effect on the retirement probability. ${ }^{10}$

Health Figure 6 shows a stylized representation of the effect of health. Consider two individuals: healthy $H_{H}(R)$ and unhealthy $H_{U}(R)$. Reduced health $H_{U}(R)$ (i.e. after a health shock) reduces earnings $Y\left[H_{U}(R)\right]$ thereby encouraging earlier retirement. This is arguably the main (first order) effect since the benefit curve $b(R)$ is unchanged (it is not a function of health) and the remaining benefits of retirement (second, third and fourth terms on the RHS of 18) constitute only about 28 percent of the total marginal benefits of retirement (or of the total marginal benefits of work, since these are equal at the optimum) for a healthy individual. In other words, the change in the marginal benefits of work due to a (relatively large) health shock is likely to be substantially larger than the change in the marginal benefits of retirement since the component of the marginal benefits of work that are amenable to change (100 percent) is larger than the component of the marginal benefits of retirement that are amenable to change (28 percent). ${ }^{11}$ Thus, ceteris paribus,

\footnotetext{
${ }^{8}$ Net pension replacement rates for OECD countries are on average 72 percent and range between 41 percent (Japan) and 112 percent (Iceland) for the median male earner (OECD, 2011).

${ }^{9} \mathrm{~A}$ natural and frequently made assumption is that wealth $A(t)$ increases remaining lifetime utility (from $t$ onwards), but at a diminishing rate $\partial q_{A}(t) / \partial A(t)=\left(\partial^{2} / \partial A(t)^{2}\right) \int_{t}^{T^{*}} U(*) e^{-\beta s} d s<0$, where $T^{*}$ denotes optimal length of life and $U(*)$ denotes the maximized utility function (i.e., along the optimal paths for the controls, state functions, and for the optimal length of life).

${ }^{10}$ There is also a longevity effect of wealth: wealthy individuals live longer (Galama 2015). This effect is arguably smaller since the analysis considers two individuals of identical health status at the age of retirement (and health status is arguably more important to longevity than is wealth) and because the longevity effect is an indirect effect, operating through the effect that wealth has on longevity and longevity in turn has on retirement (by contrast the wealth effect is a direct effect of wealth).

${ }^{11}$ It is true that the additional marginal benefits of retirement (second, third and fourth terms on the RHS of 18) may be reduced as a result of poor health, resulting in a smaller "Rest" term for an unhealthy versus a healthy individual (for simplicity these are shown in Figure 6 as being identical in size) and
} 


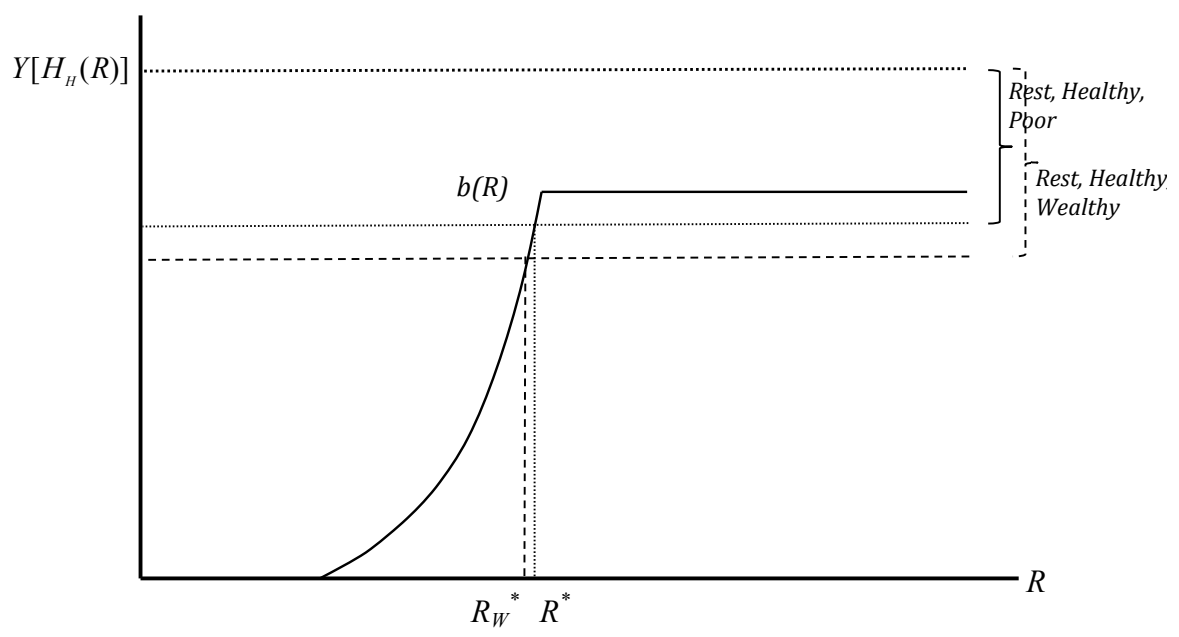

Figure 5: Stylized representation of the optimality condition for retirement (18) for a wealthy (dashed lines) and poor (dotted lines) individual, conditional on health status $H_{H}(R)$ for a healthy individual.

less healthy individuals retire earlier: ill health has a positive effect on the retirement probability.

Financial Incentives Figure 7 provides a stylized representation of the effect of financial incentives on the optimal age of retirement (18), conditional on wealth $q_{A}(R)$ for a healthy individual. The comparison here is between two identical individuals (importantly, with identical wealth [permanent income] $\left.q_{A}(R)\right)$ who differ in the financial incentives they face (the level and shape of the benefit function $b(R)$ ). Conditional on wealth the only change in the marginal benefit of retirement occurs in the first and second term on the RHS of equation (18). Both effects are captured in the shifted benefits curve (red dashed line). Also the marginal benefit of work is unchanged. As the Figure shows, more generous benefits lead to earlier retirement.

Affordability proposition The affordability proposition is the prediction that, all else held equal, the increase in the likelihood of retirement following a sudden health event is greater among those individuals with higher pension wealth, if the pension benefit is concave with age. The affordability proposition is in regard to the difference in response to a health shock. Figure 8 adds to Figure 5 a stylized representation of the same comparison between a wealthy and a poorer individual but now for a wealthy and a poor individual

therefore the effect of these terms may be to increase the optimal age of retirement somewhat. Still, since these terms constitute 28 percent of the total marginal benefit of retirement (or equivalently of the total marginal benefit of work), the effect is not likely to be dominant. 


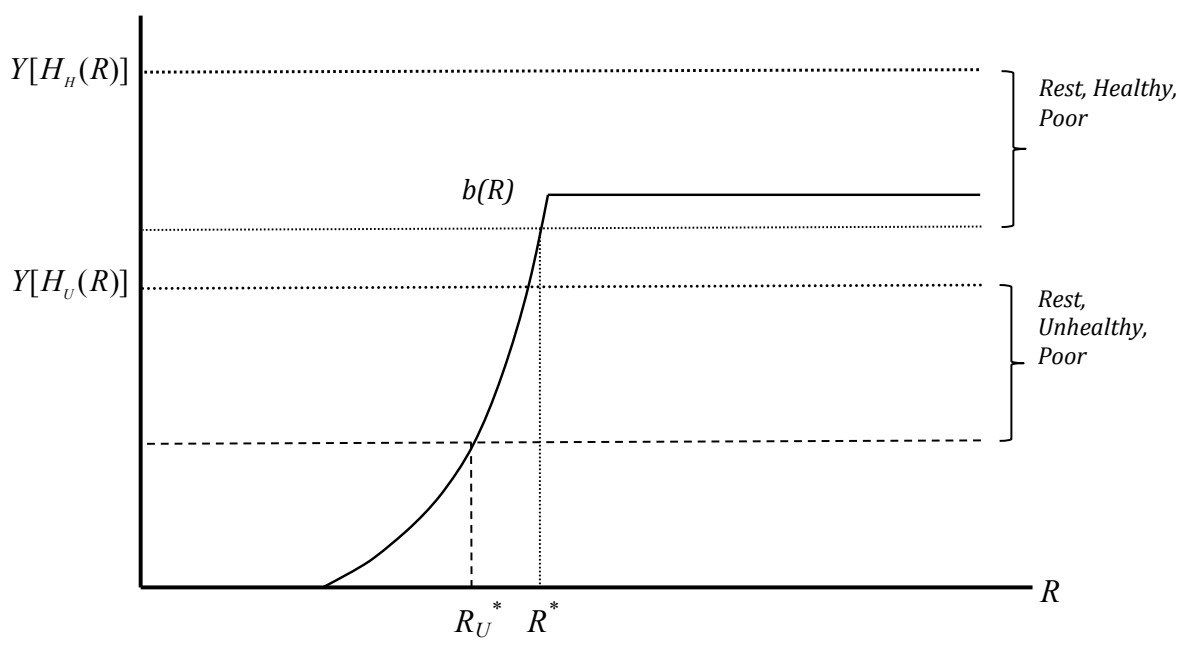

Figure 6: Stylized representation of the optimality condition for retirement (18) for a healthy (dotted lines) and unhealthy (dashed lines) individual, conditional on wealth status $q_{A}(R)$.

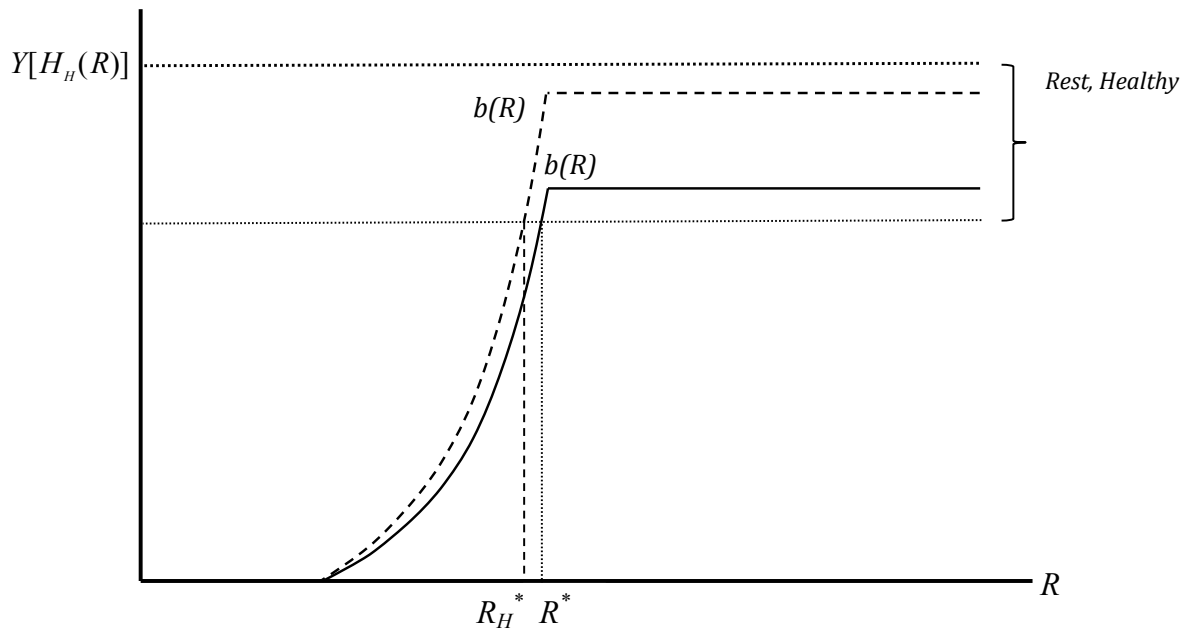

Figure 7: Stylized representation of the optimality condition for retirement (18) for an individual facing low (dotted line) and high (dashed line) financial incentives to retire, conditional on wealth (permanent income) $q_{A}(R)$, for a healthy individual. 
who are both unhealthy $H_{U}(R)$.

As Figure 8 illustrates, wealthy and poor individuals retire earlier after a health shock. Further, the size of the reduction in the optimal age of retirement is smaller for the poor $\Delta R_{P}$ than for the wealthy $\Delta R_{W}$, if the functional form of the pension benefit $b(R)$ is convex with the age of retirement $R$, as is shown. The opposite is true if the functional form of the pension benefit $b(R)$ is concave. Thus for the affordability proposition to hold, the functional dependence has to be convex. As Figures 1 and 2 show this is true for the early retirement scheme, except for a bump at age 60 , in the setting under consideration.

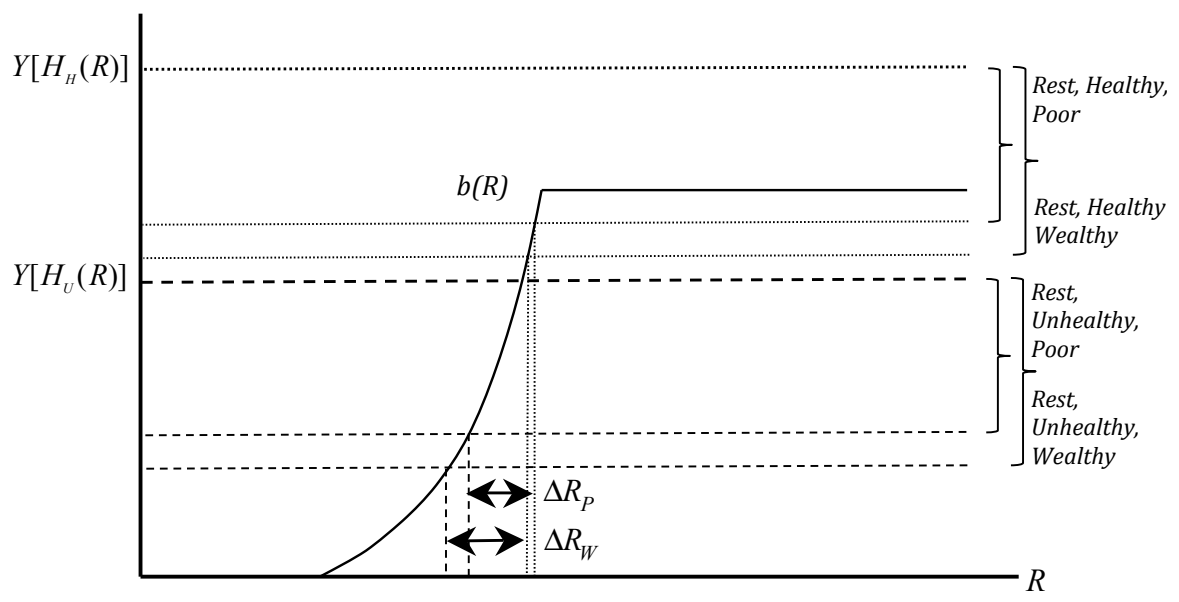

Figure 8: Figure adds to Figure 5 a stylized representation of the same graph for an unhealthy $H_{U}(R)$ individual.

Reinforcement proposition The reinforcement proposition is the prediction that, all else held equal, the effect of financial incentives on retirement decisions of healthy workers is reinforced when a health shock occurs if the pension benefit is concave with age.

The reinforcement proposition is also in regard to the difference in response to financial incentives after a health shock. Figure 9 adds to Figure 7 a stylized representation of the same comparison but for an unhealthy individual $H_{U}(R)$. Reduced health $H_{U}(R)$ reduces earnings $Y\left[H_{U}\left(R_{-}\right)\right]$thereby encouraging earlier retirement. This is arguably the main (first order) effect, following identical reasoning as was presented in the preceding discussion of affordability. As Figure 9 also illustrates, unhealthy individuals are modestly more responsive to financial incentives (compare $\Delta R_{U}$ with $\Delta R_{H}$ ). Since other factors (the "Rest" term) may also change we do not expect to find strong effects. 


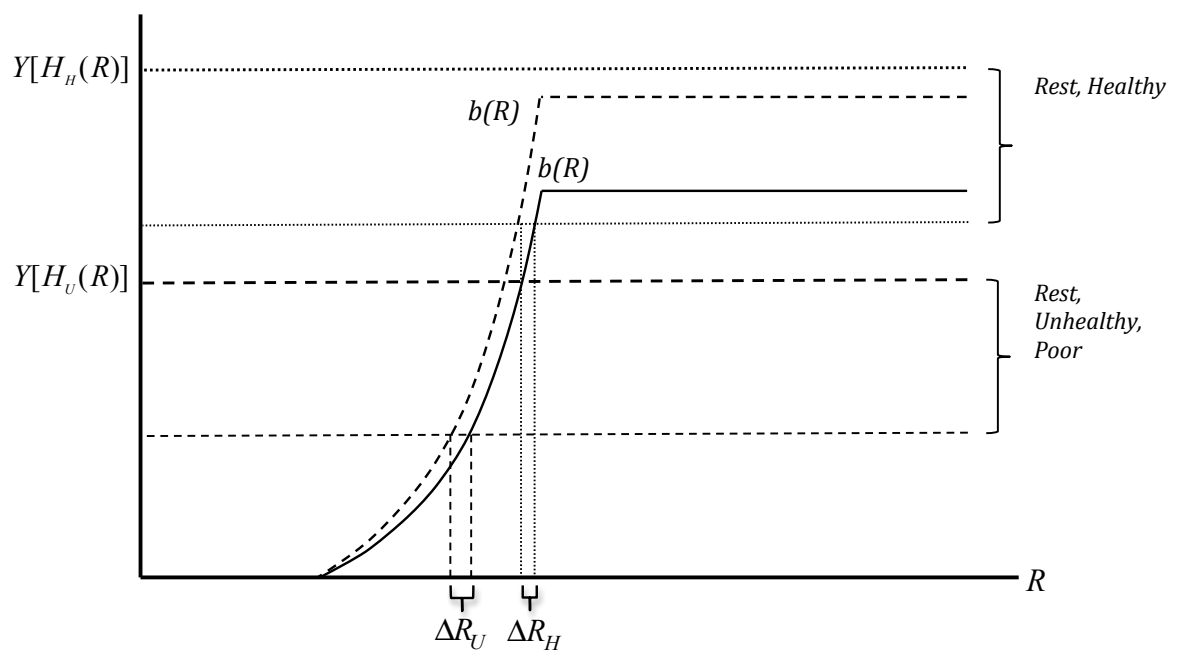

Figure 9: Figure adds to the Figure 7 a stylized representation of the same graph for an unhealthy $H_{U}(R)$ individual.

\section{Empirical strategy}

In the next sections we derive an empirically testable relation from the theory (section 4), contrast the theory with the canonical framework for retirement (Stock and Wise, 1990, section 4.1), and describe how we estimate the models (section 4.2).

The optimality condition (18) suggests the following empirical specification. First, retirement is determined by the difference between earnings from labour and the pension benefit (or replacement income). Individuals retire when benefits can be claimed and at the time when claiming is optimal. Second, retirement is influenced by the rate of change in benefits $\partial b(R) / \partial R$, since postponing retirement may be attractive when it results in higher benefits, and by expected longevity $T$. Third, besides these financial incentives, there are two more terms (the third and fourth on the RHS). Both of these are a function of wealth / permanent income. The appropriate measure of wealth would be the sum of private $A(t)$ and pension wealth $b(R) \int_{t}^{T} e^{-\delta t} d t$. In our data we only have information on pension wealth, which is by far the most important component (more than 60\%) of total household wealth for the 65-70 age group (van Ooijen et al. 2015). Since high pension wealth is generally positively correlated with private wealth, we use pension wealth as a proxy for full wealth (or permanent income $q_{A}(R)$ ). Our specification then becomes

$$
\left.p(R)=\alpha_{0}+\alpha_{1}\{Y[H(R)]-b(R)]\right\}+\alpha_{2}[b(R+1)-b(R)]+\alpha_{3} W_{R}+\alpha_{4} T
$$

where $p(R)$ is the probability of retirement at age $R, W_{R}$ is pension wealth, $T$ is expected longevity, and $\alpha_{0}, \alpha_{1}, \alpha_{2}, \alpha_{3}$, and $\alpha_{4}$ are constants. 


\subsection{Comparison with Stock and Wise}

For comparison, in modeling retirement, we also follow the option value retirement model of Stock and Wise (1990), which assumes that individuals compare the expected present value of retiring immediately (in utility terms) to the expected present value of continuing to work and retiring at the optimal age in the future:

$$
O V_{a}=\max \left(V_{j}-V_{a}\right), \quad j=a+1, \ldots, R
$$

where $V$ is the value function at age $a$ of retiring at future age $j$. This value function is computed as:

$$
V_{j}=\sum_{s=a}^{j} \rho_{s} Y_{s}^{\gamma}+\sum_{s=j+1}^{S} \rho_{s}\left[k B_{s}(j)\right]^{\gamma},
$$

and $\rho_{s}$ are the survival probabilities, $S$ is age of (certain) death, $Y_{s}$ stands for earnings, $B_{s}(j)$ for the pension benefit when retiring at age $j$. We impose $\beta=.97, \gamma=0.75$ and $k=1.5$, following previous studies (Stock and Wise, 1990; Coile and Gruber, 2007; and Wise, 2016).

The OV takes into account that individuals in their retirement decisions weigh the additional utility from an increase in total labour earnings with the reduced utility from receiving benefits over a lower number of years and the disutility of labour. Depending on the shape of the benefit function, benefits may increase if the individual retires later, and thus utility.

In addition, we consider the peak value model, one of the versions of the option value model, in which individuals compare the total discounted income from (early-)retirement benefits that they receive if they would retire today at age $a$, to the total discounted income from (early-)retirement benefits that they would receive if they would retire in the year $j$ in which they would receive the highest discounted benefits, as follows:

$$
P V_{a}=\max \left(P W_{h}-P W_{a}\right), \quad h=a+1, \ldots, R
$$

where $P W_{a}$ is the pension Wealth (PW) calculated as the net present value of the pension benefits that an individual retiring at age $a$ would receive:

$$
P W_{a}(R)=\sum_{s=R}^{64} \gamma_{t} \beta^{s-a} B_{t}^{E R}(R)+\sum_{s=65}^{T} \gamma_{t} \beta^{s-a} B_{t}^{P}(R),
$$

where $s$ is the current age, $R$ is the retirement age, $\beta$ is the discount factor, ${ }^{12} \gamma_{t}$ is the survival probability, ${ }^{13} B_{t}^{E R}$ are the early retirement benefits, and $B_{t}^{P}$ are old-age pension benefits.

\footnotetext{
${ }^{12}$ The discount factor is $3 \%$ for all individuals (hence the discount rate is 0.9708 ).

${ }^{13}$ Survival probability tables were provided by PFZW.
} 


\subsection{Model estimation}

We estimate the effect of health, and of the different financial measures explained above, on the probability of being retired in year $t+1$ conditional on working in year $t$ using regression equations of the form:

$$
P\left(R_{i t}=1\right)=F\left(\beta^{\prime} X_{i, t}+\alpha^{\prime} S_{i, t-1}+\gamma^{\prime}, W_{i, t}\right)
$$

where $S_{i, t-1}$ are health shocks between $t-2$ and $t-1,{ }^{14} W_{i, t}$ is the vector of financial incentives of individual $i$ at $t$ and $X_{i, t}$ is the vector of predictors, which include socio-demographic and socio-economic characteristics. We estimate the model as a logit. ${ }^{15}$ We cluster standard errors at the individual level to allow for within individual autocorrelation in the error term.

Three sources of variation help us to identify the effect of financial incentives on early retirement behaviour. First, the replacement rate of the OBU scheme varies by year of birth; it decreases by one percentage point per year of birth. Second, the length and size of contributions to the scheme varies between individuals. Third, individuals born after 1948 (regardless of their work history in the sector) are not eligible for OBU.

\section{Data}

Our main data source is the administrative register of the second largest pension fund in the Netherlands, the health care sector pension fund (Pensioenfonds Zorg en Welzijn, PFZW). PFZW provides pension arrangements to more than 2 million employees in the health and social-work sector. Occupations participating in the PFZW range from nurses to medical doctors, and include various supporting jobs, such as, e.g., in administration. We have access to individual employee information on gender, date of birth, working hours, wages, tenure, and pension and early-retirement entitlements for the period 1999-2003. We also use survival probability tables provided by PFZW, needed to compute pension wealth and option values.

Importantly and uniquely, we observe in the PFZW register the same personalized information that all PFZW insurees receive annually on the (early-) retirement benefits they would receive at all future possible ages if they were to retire at that age through either FLEX or OBU schemes. Thus, individuals in our sample are informed about the benefits of retiring today versus some date in the future. In computing the financial incentives, we assume that individuals choose the option that gives them the highest benefits payout at each age. As we can observe their actual (not self-reported) pension rights, based on their

\footnotetext{
${ }^{14}$ Labour-market status in our data set is the status on January 1st of each wave. Thus, we condition on health shocks that occurred sometime during the previous year to avoid reverse causality.

${ }^{15} \mathrm{We}$ also estimated these models using a complementary log-log function and the results were very similar. Results are available upon request.
} 
actual salary and seniority in the pension fund used to compute pension benefits, ${ }^{16}$ most of the measurement error typically encountered in surveys is removed. In doing so, we avoid downward bias in estimates for the effect of pension incentives, as shown by Belloni and Alessi (2009).

Individual PFZW pension data for 1999-2003 were linked to three other administrative data sources by Statistics Netherlands: (1) the municipality register ((Gemeentelijke Basis Administratie persoonsgegevens, GBA) which provides demographic information on birth date, marital status, household size, local migration and mortality; (2) the administrative employment register (Stelsel van Sociaal-Statistische Bestanden, SSB) with individual information on all employees in the Netherlands, including working hours, income from labour, and employer information; and (3) the hospital discharge register (Landelijke Medische Registratie, LMR) which includes information on diagnosis, type of admission (scheduled or emergency) and length of stay of all hospital admissions.

Labour-market status is missing in the PFZW data for some individuals in some periods. Attrition occurs: (i) when a participant has submitted an application for retirement; (ii) if the address is unknown; (iii) when the insuree becomes a so-called "sleeper" (i.e. is no longer employed in the health-care sector); or (iv) if the authority, which administers their pension entitlements at PFZW, has arrears of payment. ${ }^{17}$ Attrition is problematic as individuals may still be employed, or may be retired. Fortunately, from the SSB we can recover whether the individual is employed or not and use this information to reduce the number of missing observations.

We select individuals who are in employment and aged 55-63. Table 1 shows the median values, by age group, of the various measures of financial incentives used in the retirement models. The first column shows that the difference between earnings and pension benefits $Y(a)-b(a)$ decreases with age $a$. Most of this decrease is due to increasing pension benefits, since median wages do not decline markedly with age (column 6, $Y(a)$ ). The second column shows the change in pension benefits associated with retiring next year versus retiring this year. Consistent with figures 1 and 2, we observe the highest median value for this measure for individuals aged 58. Columns 3 shows that pension wealth $W$ increases up to age 59, with a marked decrease thereafter (note these numbers are logged). Columns 4 and 5 show median values for the Option Value and Peak Value measures, used in the Stock and Wise model specifications (equations 20 and 22). While the median OV of remaining at work is positive for all age groups, it quickly approaches zero as age approaches the statutory retirement age. A negative PV can be interpreted as a tax on further labour-force participation. The median PV turns negative at age 57, stays negative at age 58 and 59 as the scheme offers the opportunity of part-time retirement at these ages, and turns positive thereafter. ${ }^{18}$

\footnotetext{
${ }^{16}$ See Euwals et al. (2010a) for further details on calculation of the NPV. Computations of pension wealth and marginal incentives are based on Trevisan and Euwals (2011).

${ }^{17}$ Euwals et al. (2010a) provide a detailed description of attrition in the PFZW dataset. We follow them to reduce the number of missing observations.

${ }^{18}$ We observe a decrease in the PV before age 60 when some individuals can claim early-retirement
} 
Table 1: Median retirement incentives, by age.

\begin{tabular}{ccccccc}
\hline \hline Age $(a)$ & $Y(a)-b(a)$ & $\Delta b(a)$ & $\ln (W)$ & OV & PV & Earnings $Y(a)$ \\
\hline 55 & 2.141 & 0.052 & 11.014 & 94.908 & 1.942 & 2.538 \\
56 & 2.085 & 0.132 & 11.022 & 77.669 & 1.966 & 2.537 \\
57 & 2.011 & 0.089 & 11.360 & 61.790 & -0.039 & 2.527 \\
58 & 1.923 & 0.553 & 11.375 & 45.928 & -0.014 & 2.530 \\
59 & 1.445 & 0.000 & 11.358 & 34.364 & -0.643 & 2.551 \\
60 & 1.680 & 0.043 & 10.827 & 24.004 & 0.109 & 2.450 \\
61 & 1.751 & 0.149 & 10.205 & 14.959 & 0.228 & 2.346 \\
62 & 1.704 & 0.271 & 10.160 & 8.898 & 0.188 & 2.367 \\
63 & 1.400 & -0.527 & 10.255 & 4.517 & 0.092 & 2.359 \\
\hline \hline
\end{tabular}

Note: All measures, except $\ln (W)$, are expressed in units of 10,000 (Euros, except for OV, which is measured in utility units).

The hospital discharge register (LMR) provides information on both inpatient and day-care patients of all hospitals in the Netherlands from 1998 to 2005 . We observe (i) whether an individual entered the hospital, (ii) whether the admission was not planned, (iii) the admission and discharge date, and (iv) the primary diagnosis. We construct measures of new health events (proxying health shocks) using the LMR data.

We obtain indicators of the occurrence of new health problems from diagnostic information (ICD-9-CM codes). We select those codes that are likely to correspond to a new and unexpected health problem if the individual did not go to the hospital in the preceding year. ${ }^{19}$ This excludes diagnoses that can be first treated in outpatient care and those related to chronic conditions. The procedure excludes, for example, all mental-health problems and congenital diseases. Our health shock measure takes the value 1 if the individual was admitted into hospital to be treated for any of these unexpected health problems, and 0 otherwise. We use these hospital admissions deliberately to make it more likely that the shocks are exogenous to labour outcomes.

Table 2 shows descriptive statistics broken down by labour status in the next period.

benefits from OBU (see 2), since the maximum difference in pension wealth between today and the age at which individuals obtain the largest benefits decreases

${ }^{19}$ We identified with the help of a medical expert all diagnoses that could indicate new and unexpected health events in the following groups: i) infectious and parasitic diseases (some codes within 001-139); ii) neoplasms (some codes within 140-239); iii) endocrine, nutritional and metabolic diseases and immunity disorders (some codes within 204-279); iv) diseases of the nervous system and sense organs (some codes within 320-389); v) diseases of the circulatory system (some codes within 390-459); vi) diseases of the respiratory system (some codes within 460-519); vii) diseases of the digestive system (some codes within 520-579); viii) diseases of the genitourinary system (some codes within 580-629); ix) diseases of the skin and subcutaneous tissue (some codes within 680-709); $\mathrm{x}$ ) diseases of the musculoskeletal system and connective tissue (some codes within 710-739); xi) injury and poisoning (some codes within 800-999). The exact codes are available upon request. 
As expected, we see that the difference between earnings and benefits $Y(a)-b(a)$, the change in benefits $\Delta b(a)$, the option value (OV) and the peak value (PV) are lower among the group of individuals that is retired in the next period, compared to the group that stays employed. Further, the incidence of any new health event in the previous wave is $2.9 \%$ for the group of individuals that is retired in the next period, and $2.3 \%$ for the group that stays employed.

Many individuals are working part-time: the average number of hours worked is around 24. Tenure in the sector is on average 14.5 years for those that are retired and 11.5 years for the group that stays employed. The gross yearly wage ranges between 29 thousand Euros for those that remain employed and 31 thousand Euros for those that retire. Other socio-demographic covariates used in the analysis include: age dummies, marital status (married, single, widowed and divorced), household size, and Dutch nationality.

Table 2: Descriptive statistics by labour-market status in the next wave.

\begin{tabular}{lll}
\hline \hline & Retired & Employed \\
\hline$[Y(a)-b(a)] / 10,000$ & 1.556 & 2.300 \\
$\Delta b(a) / 10,000$ & 0.205 & 0.219 \\
$\ln (W)$ & 11.534 & 10.991 \\
$O V / 10,000$ & 42.848 & 81.673 \\
$P V / 10,000$ & -0.553 & 1.531 \\
$Y(a) / 10,000$ & 3.123 & 2.948 \\
Health Shock & 0.029 & 0.023 \\
Age 56 & 0.002 & 0.253 \\
Age 57 & 0.070 & 0.196 \\
Age 58 & 0.097 & 0.165 \\
Age 59 & 0.618 & 0.044 \\
Age 60 & 0.169 & 0.019 \\
Age 61 & 0.024 & 0.012 \\
Age 62 & 0.016 & 0.007 \\
Age 63 & 0.004 & 0.002 \\
Single & 0.033 & 0.033 \\
Widow & 0.018 & 0.019 \\
Divorced & 0.059 & 0.077 \\
Dutch & 0.890 & 0.891 \\
$N$ household members & 2.273 & 2.427 \\
Tenure & 14.529 & 11.515 \\
Hours worked & 24.603 & 23.666 \\
$N$ & 8,214 & 126,312 \\
\hline \hline
\end{tabular}




\section{Results}

\subsection{Effects of financial incentives and new health events}

We consider three sets of measures of financial incentives, each corresponding to one of the three alternative empirical specifications we consider. The first specification, model 1 , follows equation (19), which we derived from our theory (see section 4). Consequently, in model 1 , the probability $p(R)$ of early retirement is influenced by the difference between current earnings $Y(R)$ and the expected benefits $b(R)$ of early retirement if retiring at that age $R$, the accrual rate of benefits in the next period $b(R+1)-b(R)$ and the change in those benefits when reaching the statutory retirement age of $65 .{ }^{20}$ We compare the estimates for model 1 with those for a specification based on the option value model (model 2; equation 20) and those for a specification based on the peak value model (model 3; equation 22), which, respectively, include $\mathrm{OV}$ and $\mathrm{PV}$ as measures of financial incentives. All models control for the onset of any new and unexpected health event (as explained earlier) as a measure of a health shock. ${ }^{21}$ We exclude the $\log$ of pension wealth $\ln (W)$ from the peak-value model (model 3) because the PV is constructed using measures of pension wealth $W$. Likewise, we exclude earnings from models 1 and 2 because it is correlated with the empirical measures of financial incentives that these models do include.

We first separately examine the effects of financial incentives and the effects of health shocks on retirement decisions, and compare the results of model 1 with the option-value model's OV (model 2) and PV (model 3) specifications (Stock and Wise 1990; Coile and Gruber 2007). We then investigate the interaction of financial incentives with health shocks. Table 3 presents the marginal effect estimates of the variables of interest, while the coefficients are shown in Table 8 in the Appendix.

In our preferred specification (model 1), derived from the theoretical model presented in section 3, we find a strong and significant negative effect for the difference between labour earnings and pension benefits $Y(R)-b(R)$ : every 10,000 Euros of excess earnings over pension benefits reduces the probability of transition into ER by 1.3 percentage points. By contrast, no significant effects are found for year-to-year changes in benefits, be these either early-retirement benefits received at age a $(\Delta b(a) / 10,000)$ or retirement benefits at age 65 $(\Delta b(a=65) / 10,000)$. This may reflect the fact that this term captures a second-order effect (changes in benefits), which tends to be smaller than first-order effects (the level of benefits). Further, we may not have sufficient variation to identify the effect of both age dummies and changes in benefits, especially when the largest change in benefits for most of our sample (see 2) occurs at age 60 and OBU benefits remain flat afterwards (i.e., $\Delta b$ does not vary). There is some evidence in favour of this possibility. Re-estimating

\footnotetext{
${ }^{20}$ We add the change in the difference in benefits received at age 65 if retiring at $R+1$ compared to $R$ to the empirical specification because, in our setting, individuals receive early-retirement benefits until age 64 , and retirement benefits from age 65. These two benefits are not necessarily the same.

${ }^{21}$ We test the robustness of results using an indicator of whether the individual had an unplanned hospitalization in urgent need of treatment (an admission to the emergency department) as an alternative measure. The results are qualitatively similar and are available upon request.
} 
Table 3: Marginal effects on the probability of retirement.

\begin{tabular}{lccc}
\hline \hline & $\begin{array}{c}\text { model 1 } \\
(\text { eq. 19) }\end{array}$ & $\begin{array}{c}\text { model 2 } \\
(\mathrm{OV}, \text { eq. 20) }\end{array}$ & $\begin{array}{c}\text { model 3 } \\
(\mathrm{PV}, \text { eq. 22 })\end{array}$ \\
\hline$[Y(a)-b(a)] / 10,000$ & $\begin{array}{c}-0.0131^{* * *} \\
(0.0009)\end{array}$ & & \\
$\Delta b(a) / 10,000$ & 0.0002 & & \\
& $(0.0029)$ & & \\
$O V / 10,000$ & & $-0.0006^{* * *}$ & \\
& & $(<0.0001)$ & $-0.0085^{* * *}$ \\
$P V / 10,000$ & & & $(0.0007)$ \\
& & & $-0.0025^{* * *}$ \\
$Y(a) / 10,000$ & & & $(0.0005)$ \\
& & & \\
$\ln (W)$ & $0.0267^{* * *}$ & $0.0323^{* * *}$ & \\
& $(0.0015)$ & $(0.0020)$ & \\
$\Delta b(a=65) / 10,000$ & 0.0035 & & $0.0061^{*}$ \\
Health Shock & $(0.0035)$ & & $(0.0031)$ \\
\hline$N$ & $0.0073^{* *}$ & $0.0069^{* *}$ & 134,522 \\
AIC & $(0.0031)$ & $(0.0031)$ & $31,742.69$ \\
BIC & 134,526 & 134,526 & $31,948.69$ \\
Log-likelihood & $31,149.53$ & $31,241.24$ & $-15,850.35$ \\
\hline \hline
\end{tabular}

Note: Standard errors are in parentheses. Significance levels: ${ }^{*} 10$ percent; ${ }^{* *} 5$ percent; ${ }^{* * *} 1$ percent.

model 1 (see Table 9) including age linearly (rather than using age dummies) we find that an increase in $\Delta b(a) / 10,000$ significantly reduces ER by the same order of magnitude as $Y(R)-b(R)$ (but $\Delta b(a=65) / 10,000)$ remains statistically insignificant). This suggests that perhaps age dummies take out too much of the variation in the change in benefits, resulting in the term's statistical insignificance. An alternative explanation for this result is that the consequences for retirement benefits of postponing retirement by a year are not sufficiently well understood by the individual. However, this is unlikely given that PFZW insured individuals received individualized detailed information on the amount of (early-) retirement benefits they would receive at all future ages under both schemes.

We also find that pension wealth matters, as predicted by the theory. The probability of ER is significantly and positively affected by pension wealth (as measured by $\ln (W)$ ): a $1 \%$ rise in pension wealth $W$ leads to a 0.027 percentage points increase in the odds of ER, reflecting an income effect if leisure is a normal good.

For comparison, with the specifications based on Stock and Wise (1990), we find evidence that both the option value and the peak value have a significant negative effect 
on the probability of ER. Higher values of either act as a deterrent to ER. An increase of 10,000 Euros in the PV (OV) is estimated to reduce the probability of ER by 0.85 (0.06) percentage points. Likewise, pension wealth (in the OV model) shows a significant positive income effect, while earnings were found to reduce the likelihood of retirement: an increase of 10,000 Euros is associated with a quarter of a percentage point increase in the likelihood of retirement. The goodness of fit measures (AIC, BIC, -LL) suggest that our theoretical model best fits the data.

In all three models, our health shock measure is associated with a small, ranging from 0.61 to 0.73 percentage points, but significant increase in the probability of ER. This confirms that health events do play a role in ER decisions when financial conditions are controlled for.

To check the robustness of these estimates, we have estimated all three models using an alternative definition of retirement, which includes all exits from employment, i.e., the dependent variable takes the value one if the individual is not working in the next period (see Table 10 in the Appendix). With this alternative definition, we find that the effects of the financial variables do not differ substantially from the corresponding estimates for the ER model, but, not surprisingly, the effects of a health shock on the probability of this extended definition of retirement are generally 7-8 times higher than in the models for ER. We attribute this to the possibility that those who had a health shock that hindered them from working left the labour market (mostly) through other routes (either stopped working or went into disability) and therefore were excluded from our previous analysis. We believe this is not an undue limitation of our approach, for the evaluation of (early-) retirement policies should focus on providing evidence on how different individuals react to financial incentives conditional on them being able to work. In addition, while (early-) retirement is often not well defined in surveys, the use of administrative data guarantees that we identify as early-retired those individuals that are receiving early-retirement benefits. Last, the analysis of the effects of financial incentives on other exits from the labour market would require the use of estimated measures and therefore be prone to downward bias (Belloni and Alessi, 2009)

Job characteristics and socio-demographic variables also play an important role in explaining transitions into retirement (see Table 8 in the Appendix). The larger the number of hours worked, the lower the probability that individuals retire, capturing an apparent lower labour-market attachment among individuals that work fewer hours. Tenure in the sector does not significantly influence the retirement probability. Men are less likely to retire. The probability of early retirement is lower for single, divorced and widowed as compared to married individuals. Similarly, household size decreases the probability of early retirement.

\subsection{Heterogeneity in the effects of health shocks by socioeconomic status}

In this subsection we examine whether the effect of a health shock differs between highand low-wealth individuals (affordability proposition). For this purpose, we define high 
wealth as above the median of the distribution of pension wealth. Table 4 compares the estimated marginal effect of the probability of retiring after a health shock for high- and low-wealth individuals thus defined. We use the same specification as in model 1 and add an interaction term between our measure of a new and unexpected health shock and a binary indicator for high wealth.

Table 4: Average marginal effect of health shock by wealth.

\begin{tabular}{lc}
\hline & Retirement \\
\hline Below-median $W$ & $0.0001(0.0049)$ \\
Above-median $W$ & $0.0119^{* *}(0.0041)$ \\
\hline
\end{tabular}

Notes: The difference in these two marginal effects is significant at the $10 \%$ level (p-value $=0.07$ )

As Table 4 shows, we find a significant difference in the likelihood of retirement between poorer and richer individuals following a health shock, with a health shock having a substantially larger impact on the likelihood of retirement for richer individuals. Moreover, a health shock does not significantly increase the probability of retiring for poorer individuals. The difference of 1.18 percentage points is large relative to the effect of a health shock found earlier (0.73 percentage points; see model 1, Table 3), suggesting the presence of an important degree of heterogeneity in responses to health shocks by wealth.

In order to test whether this result is driven by unobserved differences in skill levels, we estimate the corresponding average marginal effects for individuals above and below median earnings (see Table 5) and find that for the high earners the effect is positive and significant while for low earners it is not. The difference between average marginal effects is, however, not statistically significant, suggesting that differences in the effect of health shocks by wealth $W$ are not driven by differences in skill levels.

Table 5: Average marginal effect of health shock by earnings.

\begin{tabular}{cc}
\hline & Retirement \\
\hline Below-median earnings & $0.0093(0.0071)$ \\
Above-median earnings & $0.0071^{* *}(0.0036)$ \\
\hline
\end{tabular}

Notes: The difference in these marginal effects is not significant at the $10 \%$ level.

As a further robustness check, we use disposable household income from tax records (Regionaal Inkomens Onderzoek, RIO) available for about one third of our respondents. ${ }^{22}$ Using this alternative definition, we also find that a health shock has a significantly larger impact on the likelihood of retirement for richer individuals $(p-$ value $=0.046)$.

\footnotetext{
${ }^{22} \mathrm{RIO}$ is a longitudinal administrative register that covers one third of the Dutch population and contains information on personal and household disposable income that is computed as gross income from wages, profits and wealth, earnings plus transfers less taxes and premiums.
} 
Finally, as a check on whether these differences across socioeconomic status are driven by differences in the types of health shock, Table 6 shows the proportion of individuals affected by the different medical conditions that in aggregate constitute the health shock measure. Note that there are no remarkable differences in these proportions between highand low-wealth individuals under the three alternative definitions. The one exception is for respiratory diseases, which are six times more likely to occur for low pension wealth $W$ individuals. However, we see no such differences for the household income and earnings measures.

Table 6: Proportion of individuals with different types of health shocks, by income.

\begin{tabular}{|l|cc|cc|cc|}
\hline & \begin{tabular}{|}
$W<$ \\
median
\end{tabular} & $\begin{array}{c}W> \\
\text { median }\end{array}$ & $\begin{array}{c}\text { HHincome }< \\
\text { median }\end{array}$ & $\begin{array}{c}\text { HHincome } \\
\text { median }\end{array}$ & $\begin{array}{c}\text { Earnings }< \\
\text { median }\end{array}$ & $\begin{array}{c}\text { Earnings }> \\
\text { median }\end{array}$ \\
\hline Infectious & 0.004 & 0.0004 & 0.0003 & 0.0004 & 0.0003 & 0.0004 \\
Cancer & 0.0070 & 0.0063 & 0.0052 & 0.0064 & 0.0066 & 0.0067 \\
Endocrine & 0.0000 & $<0.0001$ & 0.0000 & $<0.0001$ & 0.0000 & $<0.0001$ \\
Nervous & 0.0029 & 0.0028 & 0.0024 & 0.0028 & 0.0027 & 0.0029 \\
Circulatory & 0.0027 & 0.0045 & 0.0033 & 0.0034 & 0.0032 & 0.0037 \\
Stroke & 0.0011 & 0.0011 & 0.0011 & 0.0011 & 0.0013 & 0.001 \\
Respiratory & 0.0050 & 0.0008 & 0.0007 & 0.0007 & 0.0006 & 0.0006 \\
Digestive & 0.0012 & 0.0014 & 0.0014 & 0.0012 & 0.0013 & 0.0013 \\
Genitourinary & 0.0026 & 0.0015 & 0.0027 & 0.0021 & 0.0025 & 0.0019 \\
Skin & 0.0002 & 0.0003 & 0.0004 & 0.0003 & 0.0003 & 0.0002 \\
Musculoskeletal & 0.0016 & 0.0011 & 0.0011 & 0.0012 & 0.0015 & 0.0012 \\
Injury & 0.0038 & 0.0037 & 0.0037 & 0.0036 & 0.0040 & 0.0037 \\
\hline \hline
\end{tabular}

\subsection{Heterogeneity in the effect of financial variables by the presence of health shocks}

Next we focus on whether the effects of financial incentives change in the presence of a health shock. In order to test for a reinforcement effect, we use specifications where both the difference between earnings and benefits $Y(R)-b(R)$ and the annual increase in benefits $\Delta b(R)$ are interacted with the health shock indicator. The estimates in Table 7 show the difference between the marginal effect of financial incentives for an individual with a health shock and the marginal effect of financial incentives for an individual without a health shock.

We find a significant heterogeneous effect for the difference between earnings and benefits $Y(R)-b(R)$. The sign of the estimate suggests that an increase in this gap reduces the likelihood of retirement to a greater extent for individuals who had a health shock: for every increase of 10,000 Euro in the difference between earnings and benefits 
Table 7: Difference in the average marginal effect of financial incentives by health

\begin{tabular}{lc}
\hline & Retirement \\
\hline Earnings-Benefits & $-0.0093^{* *}(0.0047)$ \\
Change in benefits & $0.0095(0.0074)$ \\
\hline
\end{tabular}

the likelihood of retirement is reduced by 0.93 percentage points more for an individual with a health shock (compared to an - otherwise identical individual who did not have a health shock). This is a relatively large difference if we consider that the corresponding effect in the model without interactions is a reduction by 0.73 percentage points for every 10,000 Euro (see model 1, Table 3). Note that the difference of the marginal effect of the change in benefits is of the same magnitude as the difference in the marginal effect of the gap between earnings and benefits. It is, however, statistically insignificant due to a larger standard error.

Figure 10 provides further detail on the effect of the financial incentive measure that is the difference between earnings and benefits for individuals who did and who did not have a new and unexpected health shock: it shows the marginal effect computed at different points of the $Y(R)-b(R)$ distribution for the two groups (with and without a health shock). First, note that for high values of this measure, that is, for individuals who would incur a large income loss upon retiring early, the effect is close to zero both for those with and without a health shock. In other words, a change of 10,000 Euros in the difference between earnings and benefits does not have a significant effect on the retirement probability for these individuals, because the drop in income $Y(R)-b(R)$ resulting from ER is too large. Second, the effect becomes larger in magnitude, and more so for those with a health shock, for negative values of this financial measure, that is, for individuals whose pension benefit exceeds their earnings. For example, the marginal effect of $Y(R)-b(R)$ when the difference equals zero is twice as large for the unhealthy (about -0.04) compared to the healthy (-0.02). This confirms the prediction from the theoretical model that ill health reinforces the effect of financial incentives, given the convex shape of the benefit function in our institutional setting.

\section{Conclusion and discussion}

It is well known that both adverse health events and financial incentives affect the decision to retire (early) from the labour force. What is less well known is how these effects can be understood theoretically and how they interact in retirement decisions. This paper aims to fill these gaps. It contributes theoretically by proposing an extended model of health capital that explicitly models the effect of financial incentives, health, wealth, longevity and the optimal age of retirement. The model generates new testable predictions about the interaction between financial incentives and health in retirement, which we then 


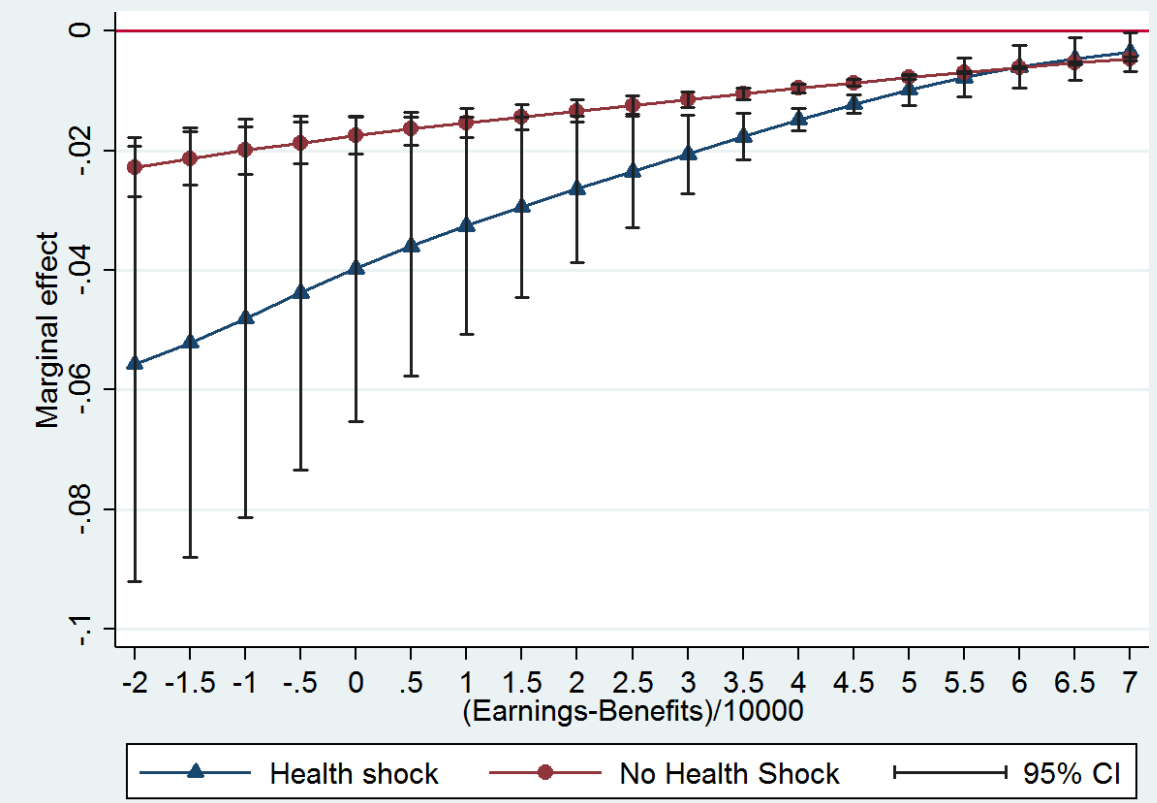

Figure 10: Distribution of the average marginal effect of the gap between earnings and benefits on early-retirement as a function of the gap, by health status. Authors' calculations based on the estimated model 1. 
empirically examine using a rich source of data on the retirement behaviour of Dutch workers.

Our theoretical findings are as follows. First, our model predicts that, ceteris paribus, wealthier individuals will retire earlier: they value leisure relatively more and can afford to retire. Secondly, because a health shock reduces the marginal benefits of work versus retirement, the theory predicts that, all else equal, individuals with reduced health will retire earlier. Third, more generous retirement benefits will, ceteris paribus, lead to earlier retirement. None of these predictions are very surprising. The usefulness of the theoretical model becomes rather more apparent when considering the interactions between health, wealth and financial incentives. From the theory we derive two novel propositions: (i) that wealthier individuals (compared to poorer individuals) are more likely to retire for health reasons (affordability proposition), and (ii) that health problems make older workers more responsive to financial incentives encouraging retirement (reinforcement proposition). These predictions are valid if the benefits function is convex with age, as in our data.

Each of these theoretical predictions we subject to empirical testing with data on the retirement patterns of Dutch health-care workers. Exploiting quasi-exogenous variation in health as measured by unexpected hospital admissions, and exogenous variation in financial incentives for retirement over the period 1999-2003, we estimate the marginal effects of financial incentives and of health shocks separately, as well as their interaction, on the probability of early retirement. Our empirical findings are as follows. First, the difference between earnings and benefits reduces the probability of early retirement substantially. Second, we establish the expected positive effect of pension wealth on earlier retirement: a 1 percent rise in pension wealth increases the probability of early retirement by 0.027 percentage points, reflecting an income effect if leisure is a normal good. Third, a health shock raises the retirement probability: the increase is significant but small $(0.007$ percentage points).

We also find support for our affordability proposition: the effect of a health shock is significant for above median pension wealth individuals, but not for those with below median pension wealth. Further, we find that the effect of a health shock on retirement is significantly larger for individuals living in a high-income household. We also find empirical support for our reinforcement proposition whereby the effect of financial incentives encouraging retirement, in this case a smaller gap between earnings and pension benefits, is larger for individuals who recently suffered from a health shock.

The limitations of our analysis are mainly related to the focus on ER and the abstraction from alternative exit routes from the labour market. As we have argued, this focus is justified to provide evidence on how individuals react to financial incentives, conditional on them being able to work. However, to the extent that the set of rules governing DI exits do not discriminate perfectly between those who are able and unable to work (allowing some workers to take the DI route after a health shock who would still be able to work in some capacity), our estimates for the effects of a health shock on ER may be considered a lower bound.

This suggests important avenues for further research. Contingent on the availability 
of data of similar quality, our theoretical model and empirical specifications could be extended to accommodate competing exits from the labour force. Another avenue would be to test whether the empirical results we have documented are valid in other contexts/countries and whether such replication (or lack thereof) is related to the shape of the benefits function in a way that is consistent with the theory. The theoretical predictions of affordability and reinforcement rely on the convexity of the benefit function with age. If the function were concave, one would expect to observe the opposite patterns. Thus, (i) poorer individuals would be more likely to retire for health reasons, and (ii) health problems would make older workers less responsive to financial incentives for retirement. This points to the possibility that differences in responses to financial incentives and health shocks across countries might not only be explained by difference in the generosity of retirement benefits, but also by whether the benefit function is concave or convex.

As for the policy implications, our theoretical and empirical findings point to the importance of assessing financial incentives for their potential reinforcement of health shocks. Our results confirm the potential of reforms reducing exits by tweaking the financial incentives of retirement systems. Of further added value in this context is evidence that the effect of financial incentives persist even for people who had a health shock. In fact, the effects of financial incentives are greater for those that suffered a health shock. Notwithstanding the caveats discussed above, and subject to additional evidence from other contexts, we believe that this is a result of relevance for retirement policies. 


\section{Acknowledgements}

Research reported in this publication was supported by the National Institute on Aging of the National Institutes of Health under Award Numbers K02AG042452 and R01AG037398. The content is solely the responsibility of the authors and does not necessarily represent the official views of the National Institutes of Health. Pilar García-Gómez acknowledges support from a Postdoctoral Fellow of the Netherlands Organisation for Scientific Research's Innovational Research Incentives Scheme (Veni). Titus Galama is grateful to the School of Economics of Erasmus University Rotterdam for a Visiting Professorship in the Economics of Human Capital. Angel López-Nicolás acknowledges support from the Programa Nacional de Español de R+D+I ECO-2013-48217 (FEPS-MINECO). We are grateful to Rob Alessie, Maarten Lindeboom and seminar participants at the XXXI Jornadas AES in Palma de Mallorca, the 8th iHEA World Congress in Toronto, the 11th iHEA World Congress in Milan, and the IV Health Economics and Ageing Workshop at FEDEA in Madrid for valuable comments. We are also grateful to Isabelle Soerjomataram for valuable help with identifying new health events from LMR data, and to Esen Erdogan-Ciftci, Rob Euwals, Elisabetta Trevisan and Annemiek van Vuren for their collaboration in preparing the datasets and providing institutional details. PGGM / PFZW and Statistics Netherlands are acknowledged for access to the data. 


\section{References}

Banks, J., Blundell, R. and Tanner, S., "Is there a retirement-savings puzzle?" American Economic Review (1998), pp.769-788.

Banks J., Emmerson C. and Tetlow G. "Healthy retirement or unhealthy inactivity: how important are financial incentives in explaining retirement?" The Institute for Fiscal Studies Working Paper (2007). London.

Belloni M. and Alessie R. "The importance of financial incentives on retirement choices: New evidence for Italy." Labour Economics (2009), 16, 578-588.

Bernheim, B.D., Skinner, J. and Weinberg, S. "What accounts for the variation in retirement wealth among US households?" American Economic Review, (2001), pp.832-857.

Bound J. "Self-reported versus objective measures of health in retirement models." Journal of Human Resources (1991), 26, 106-138.

Bound J., Schoenbaum M., Stinebrickner T. and Waidman T. "The dynamic effects of health on the labour force transition of older workers." Labour Economics (1999), 6, 179-202.

Caputo, M.R. (2005), Foundations of Dynamic Economic Analysis. Cambridge University Press.

Coile C. and Gruber J. "Future social security entitlements and the retirement decision." The Review of Economics and Statistics (2007), 89(2), 234-246.

Currie J. and Madrian B. "Health, health insurance and labour market" in Handbook of labour economics, Volume 3C, Amsterdam, New York and Oxford: Elsevier Science, North Holland, (1999), 3309-3416

Disney R., Emmerson C. and Wakefield M. "Ill health and retirement in Britain: A panel data-based analysis." Journal of Health Economics (2006), 25, 621-649.

Dobkin, C., Finkelstein, A., Kluender, R. and Notowidigdo, M.J., "The economic consequences of hospital admissions." National Bureau of Economic Research Working Paper, No. w22288 (2016).

Ehrlich, I. and H. Chuma "A Model of the Demand for Longevity and the Value of Life Extension", Journal of Political Economy, (1990), 98(4): 761-782. 
Euwals R. Trevisan E. and. van Vuren A, "Labour Market Exit in the Health Care Sector: First Results from Administrative Data" Netspar Discussion Paper (2010a), 05/2010-016.

Euwals, R. van Vuuren D., and Wolthoff R. "Early retirement behaviour in the Netherlands" De Economist (2010b), 158, 209-236.

Euwals R, van Vuren A, van Vuuren D. "The decline of early retirement pathways in the Netherlands An empirical analysis for the health care sector" International Social Security Review (2012), 65, 101-122.

Galama, T.J. "A contribution to Health Capital Theory", CESR Working Paper 2015-004 (2015).

García-Gómez P., van Kippersluis H., O’Donnell O., van Doorslaer E. " Long-Term and Spillover Effects of Health Shocks on Employment and Income." Journal of Human Resources (2013), 48(4): 873-909.

Grossman, M. (1972a), The Demand for Health-A Theoretical and Empirical Investigation, New York: National Bureau of Economic Research.

Grossman, M. (1972b), "On the Concept of Health Capital and the Demand for Health", Journal of Political Economy, 80(2): 223-255.

Gruber J. and Wise David A. "Social security programs and retirement around the world: micro-estimation." The University of Chicago Press, Chicago, IL. (2004).

Hagan R., Jones A.M. and Rice N. "Health shocks and the hazard rate of early retirement in the ECHP" Swiss Journal of Economics and Statistics (2008), 144, 323-335.

Halla, M. and Zweimüller M. "The Effect of Health on Income: Quasi-Experimental Evidence from Commuting Accidents." Labour Economics (2013), 24, 23-28.

Hurd, M., and Rohwedder, S. "The Retirement-Consumption Puzzle: Anticipated and Actual Declines in Spending at Retirement." National Bureau of Economic Research, Working Paper 9586 (2003).

Hurd, M., and Rohwedder, S.. "Some Answers to the Retirement-Consumption Puzzle." National Bureau of Economic Research, Working Paper 12057 (2006).

Hurd, M., and Rohwedder, S. "Heterogeneity in spending change at retirement" The 
Journal of the Economics of Ageing 1-2, 60-71 (2013).

Kapteyn, A., and De Vos, K., "Social Security and Retirement in The Netherlands," in: Jonathan Gruber and David A. Wise (eds.), Social Security and Retirement around the World, Chicago University Press, 1999, 269-304.

Kerkhofs M., Lindeboom M. and Theeuwes J. "Retirement, financial incentives and health." Journal of Labour Economics (1999), 6, 203-227.

Kuhn, M., Wrzaczek, S., Prskawetz, A. and Feichtinger, G., "Optimal choice of health and retirement in a life-cycle model. " Journal of Economic Theory (2015), 158, pp.186-212.

Lazear, E.P., (1986), "Retirement From the Labor Force", in Handbook of Labor Economics, Ashenfelter, O and Layaro R. (eds) Chapter 5, Vol. 1, Elsevier Science Publishers BV: Amsterdam, The Netherlands, 305-355.

Lindeboom, M. and Kerkhofs, M. "Health and Work of the Elderly: Subjective Health Measures, Reporting Errors and Endogeneity in the Relationship between Health and Work" Journal of Applied Econometrics (2009), 24(6): 1024-46.

Lindeboom, M. "Health and work of older workers." In Elgar Companion to Health Economics Jones, A.M. (ed). Edward Elgar: Aldershot (2012).

Lindeboom, M., Llena Nozal, A. and van der Klaauw, B.. "Health shocks, disability and work." Labour Economics (2016), 43, 186-200.

Lumsdaine, R.L. and Mitchell, O.S. "New developments in the economic analysis of retirement." In Handbook of Labor Economics Vol 3. Ashenfelter O.C, Card, D. (eds). Elsevier: Amsterdam (1999).

Møller Dano, A. "Road Injuries and Long-Run Effects on Income and Employment." Health Economics (2005),14(9): 955-970.

OECD Pensions at a Glance: retirement-income systems in OECD and G20 Countries. Paris (2011).

Roberts, J., Jones, A.M., and Rice, N. "Sick of work or too sick to work? Evidence on self reported health shocks and early retirement from the BHPS." Economic Modeling (2010), 27 (4), 866-880.

Seierstad, A. and K. Sydsaeter "Optimal Control Theory With Economic Applications", In: Advanced Textbooks in Economics, Volume 24, Series Editors: C.J. Bliss and M.D. 
Intriligator, Elsevier, North Holland (1987).

Stock, J. and Wise, D. "Pension, the option value of work and retirement." Econometrica (1990), (58) 5, 11511180.

Trevisan, E. and Euwals, R. "Early Retirement and Financial Incentives: Differences Between High and Low Wage Earners." CPB Discussion Paper 195 (2011).

Van Ooijen, R., Alessie, R. and Kalwij, A. "Saving Behavior and Portfolio Choice After Retirement." De Economist (2015), 163, 353-404.

Wise, David A. "Social security programs and retirement around the world: disability insurance programs and retirement." The University of Chicago Press, Chicago, IL. (2016). 
Table 8: Coefficients and (SE) of all the variables included in the models.

\begin{tabular}{|c|c|c|c|}
\hline & M1 & M2 & M3 \\
\hline$[Y(a)-b(a)] / 10,000$ & $\begin{array}{c}-0.0131^{* * *} \\
(0.0009)\end{array}$ & & \\
\hline$\Delta b(a) / 10,000$ & $\begin{array}{c}0.0002 \\
(0.0029)\end{array}$ & & \\
\hline$\Delta b(a=65) / 10,000$ & $\begin{array}{c}0.0035 \\
(0.0035)\end{array}$ & & \\
\hline$O V / 10,000$ & & $\begin{array}{c}-0.0006^{* * *} \\
(<0.0001)\end{array}$ & \\
\hline$P V / 10,000$ & & & $\begin{array}{c}-0.0085^{* * * *} \\
(0.0007)\end{array}$ \\
\hline$Y(a) / 10,000$ & & & $\begin{array}{c}-0.0025^{* * *} \\
(0.0005)\end{array}$ \\
\hline $\ln (W)$ & $\begin{array}{c}0.0267^{* * * *} \\
(0.0015)\end{array}$ & $\begin{array}{c}0.0323^{* * *} \\
(0.0020)\end{array}$ & \\
\hline Health Shock & $\begin{array}{c}0.0073^{* *} \\
(0.0031)\end{array}$ & $\begin{array}{c}0.0069^{* *} \\
(0.0031)\end{array}$ & $\begin{array}{l}0.0061 * \\
(0.0031)\end{array}$ \\
\hline Age 57 & $\begin{array}{c}0.0201^{* * *} \\
(0.0009)\end{array}$ & $\begin{array}{c}0.0192^{* * *} \\
(0.0008)\end{array}$ & $\begin{array}{c}0.0183^{* * *} \\
(0.0008)\end{array}$ \\
\hline Age 58 & $\begin{array}{c}0.0329 * * * \\
(0.0014)\end{array}$ & $\begin{array}{c}0.0228^{* * *} \\
(0.0010)\end{array}$ & $\begin{array}{c}0.0294^{* * *} \\
(0.0011)\end{array}$ \\
\hline Age 59 & $\begin{array}{c}0.3941^{* * *} \\
(0.0066)\end{array}$ & $\begin{array}{c}0.3219 * * * \\
(0.0108)\end{array}$ & $\begin{array}{c}0.3774^{* * *} \\
(0.0090)\end{array}$ \\
\hline Age 60 & $\begin{array}{c}0.3676^{* * *} \\
(0.0084)\end{array}$ & $\begin{array}{c}0.2562^{* * *} \\
(0.0117)\end{array}$ & $\begin{array}{c}0.3414^{* * *} \\
(0.0086)\end{array}$ \\
\hline Age 61 & $\begin{array}{c}0.1454^{* * *} \\
(0.0102)\end{array}$ & $\begin{array}{c}0.0820 * * * \\
(0.0074)\end{array}$ & $\begin{array}{c}0.1338^{* * *} \\
(0.0088)\end{array}$ \\
\hline Age 62 & $\begin{array}{c}0.1508^{* * * *} \\
(0.0137)\end{array}$ & $\begin{array}{c}0.0796 * * * \\
(0.0095)\end{array}$ & $\begin{array}{c}0.1419^{* * * *} \\
(0.0114)\end{array}$ \\
\hline Age 63 & $\begin{array}{c}0.1556^{* * *} \\
(0.0410)\end{array}$ & $\begin{array}{c}0.0770^{* * *} \\
(0.0160)\end{array}$ & $\begin{array}{c}0.1318^{* * *} \\
(0.0206)\end{array}$ \\
\hline Male & $\begin{array}{c}-0.0144^{* * *} \\
(0.0016)\end{array}$ & $\begin{array}{c}-0.0142^{* * *} \\
(0.0016)\end{array}$ & $\begin{array}{c}-0.0184^{* * * *} \\
(0.0015)\end{array}$ \\
\hline Year 2000 & $\begin{array}{c}0.0118^{* * * *} \\
(0.0016)\end{array}$ & $\begin{array}{c}0.0120^{* * *} \\
(0.0016)\end{array}$ & $\begin{array}{c}0.0151^{* * *} \\
(0.0016)\end{array}$ \\
\hline Year 2001 & $\begin{array}{c}-0.0047^{* * *} \\
(0.0015)\end{array}$ & $\begin{array}{c}-0.0044^{* * *} \\
(0.0015)\end{array}$ & $\begin{array}{l}-0.0004 \\
(0.0015)\end{array}$ \\
\hline Year 2002 & $\begin{array}{c}0.0118^{* * *} \\
(0.0015)\end{array}$ & $\begin{array}{c}0.0122^{* * *} \\
(0.0015)\end{array}$ & $\begin{array}{c}0.0171^{* * *} \\
(0.0015)\end{array}$ \\
\hline Widow & $\begin{array}{c}-0.0127^{* * *} \\
(0.0031)\end{array}$ & $\begin{array}{c}-0.0128^{* * *} \\
(0.0032)\end{array}$ & $\begin{array}{c}-0.0134^{* * *} \\
(0.0031)\end{array}$ \\
\hline Divorced & $\begin{array}{c}-0.0067^{* * *} \\
(0.0020)\end{array}$ & $\begin{array}{c}-0.0067^{* * *} \\
(0.0020)\end{array}$ & $\begin{array}{c}-0.0087^{* * *} \\
(0.0020)\end{array}$ \\
\hline Single & $\begin{array}{c}-0.0051^{*} \\
(0.0030)\end{array}$ & $\begin{array}{c}-0.0073^{* *} \\
(0.0029)\end{array}$ & $\begin{array}{c}-0.011^{* * *} \\
(0.0027)\end{array}$ \\
\hline Dutch & $\begin{array}{c}0.0057^{* * * *} \\
(0.0015)\end{array}$ & $\begin{array}{c}0.0054^{* * *} \\
(0.0015)\end{array}$ & $\begin{array}{c}0.0063^{* * *} \\
(0.0015)\end{array}$ \\
\hline$N$ household members & $\begin{array}{c}-0.0035^{* * *} \\
(0.0008)\end{array}$ & $\begin{array}{c}-0.0035^{* * * *} \\
(0.0008)\end{array}$ & $\begin{array}{c}-0.0036^{* * *} \\
(0.0008)\end{array}$ \\
\hline Tenure & $\begin{array}{c}0.0001 \\
(0.0002)\end{array}$ & $\begin{array}{c}0.0002 \\
(0.0002)\end{array}$ & $\begin{array}{c}0.0033^{* * *} \\
(0.0001)\end{array}$ \\
\hline Hours & $\begin{array}{c}-0.0014^{* * *} \\
(0.0001)\end{array}$ & $\begin{array}{c}-0.0013^{* * *} \\
(<0.0001)\end{array}$ & $\begin{array}{c}-0.0008^{* * *} \\
(0.0001)\end{array}$ \\
\hline$N$ & 134,526 & 134,526 & 134,522 \\
\hline AIC & $31,149.53$ & $31,241.24$ & $31,742.69$ \\
\hline $\mathrm{BIC}$ & $31,375.14$ & $31,447.24$ & $31,948.69$ \\
\hline Log-likelihood & $-15,551.76$ & $-15,599.62$ & $-15,850.35$ \\
\hline
\end{tabular}

Note: Standard errors are in parentheses. Significance levels: ${ }^{*} 10$ percent; ${ }^{* *} 5$ percent; ${ }^{* * *} 1$ percent. 
Table 9: Marginal effects on the probability of retirement using linear age trend.

\begin{tabular}{lccc}
\hline \hline & $\begin{array}{c}\text { model 1 } \\
(\text { eq. 19) }\end{array}$ & $\begin{array}{c}\text { model } 2 \\
(\mathrm{OV}, \text { eq. 20) }\end{array}$ & $\begin{array}{c}\text { model 3 } \\
(\mathrm{PV}, \text { eq. 22) }\end{array}$ \\
\hline$[Y(a)-b(a)] / 10,000$ & $-0.0149^{* * *}$ & & \\
& $(0.0010)$ & & \\
$\Delta b(a) / 10,000$ & $-0.0149^{* * *}$ & & \\
& $(0.0010)$ & & \\
$O V / 10,000$ & & $-0.0008^{* * *}$ & \\
& & $(<0.0001)$ & $-0.0136^{* * *}$ \\
$P V / 10,000$ & & & $(0.0008)$ \\
& & & $-0.0064^{* * *}$ \\
$Y(a) / 10,000$ & & & $(0.0006)$ \\
& & & \\
$\ln (W)$ & $0.0320^{* * *}$ & $0.0399^{* * *}$ & \\
& $(0.0014)$ & $(0.0021)$ & \\
$\Delta b(a=65) / 10,000$ & 0.0024 & & $0.0077^{* *}$ \\
Health Shock & $(0.0027)$ & & $(0.0033)$ \\
& $0.0086^{* * *}$ & $0.0091^{* * *}$ & 134,522 \\
$N$ & $(0.0032)$ & $(0.0033)$ & $34,083.56$ \\
AIC & 134,526 & 134,526 & $34,230.70$ \\
BIC & $32,525.56$ & $34,055.29$ & $-17,026.80$ \\
\hline Log-likelihood & $32,692.33$ & $34,202.43$ & \\
\hline \hline
\end{tabular}

Note: Standard errors are in parentheses. Significance levels: $* 10$ percent; ${ }^{* *} 5$ percent; *** 1 percent. 
Table 10: Marginal effects on the probability of extended retirement.

\begin{tabular}{lccc}
\hline \hline & $\begin{array}{c}\text { model 1 } \\
\text { (eq. 19) }\end{array}$ & $\begin{array}{c}\text { model 2 } \\
(\mathrm{OV}, \text { eq. 20) }\end{array}$ & $\begin{array}{c}\text { model 3 } \\
(\mathrm{PV}, \text { eq. 22 })\end{array}$ \\
\hline$Y Y(a)-b(a)] / 10,000$ & $-0.0146^{* * *}$ & & \\
& $(0.0011)$ & & \\
$\Delta b(a) / 10,000$ & 0.0012 & & \\
& $(0.0038)$ & & \\
$O V / 10,000$ & & $-0.0005^{* * *}$ & \\
& & $(<0.0001)$ & $-0.0090^{* * *}$ \\
$P V / 10,000$ & & & $(0.0008)$ \\
& & & $-0.0024^{* * *}$ \\
$Y(a) / 10,000$ & & & $(0.0005)$ \\
& & & \\
$\ln (W)$ & $0.0208^{* * *}$ & $0.0235^{* * *}$ & \\
& $(0.0022)$ & $(0.0026)$ & \\
$\Delta b(a=65) / 10,000$ & 0.0068 & & $0.0365^{* * *}$ \\
& $(0.0047)$ & & $(0.0046)$ \\
Health Shock & $0.0374^{* * *}$ & $0.0369^{* * *}$ & 136,268 \\
& $(0.0046)$ & $(0.0046)$ & $46,186.04$ \\
$N$ & 136,272 & 136,272 & $46,392.31$ \\
AIC & $46,027.07$ & $46,190.10$ & $-23,072.02$ \\
BIC & $46,252.99$ & $46,396.37$ & \\
Log-likelihood & $-22,990.54$ & $-23,074.10$ & \\
\hline \hline
\end{tabular}

Note: Standard errors are in parentheses. Significance levels: $* 10$ percent; ${ }^{* *} 5$ percent; *** 1 percent. 